\title{
əLarge-Scale Conditions for Reintensification after the Extratropical Transition of Tropical Cyclones in the Western North Pacific Ocean $\mathscr{O}$
}

\author{
WATARU YANASE AND UdAI SHIMADA \\ Meteorological Research Institute, Japan Meteorological Agency, Tsukuba, Japan \\ NAO TAKAMURA \\ Forecast Division, Japan Meteorological Agency, Tokyo, Japan
}

(Manuscript received 9 January 2020, in final form 9 August 2020)

\begin{abstract}
Tropical cyclones that complete extratropical transition (ETTCs) in the western North Pacific are statistically analyzed to clarify the large-scale conditions for their reintensification. A dataset of ETTCs is grouped into intensifying, dissipating, and neutral classes based on the best track data documented by the Japan Meteorological Agency during the period 1979-2018. Intensifying ETTCs are most frequent in September-October, whereas dissipating ETTCs are most frequent in the later season, October-November. Intensifying ETTCs occur at higher latitudes than dissipating ETTCs, where the upper levels are characterized by high potential vorticity (PV) and a steep horizontal gradient of PV. The composite analysis demonstrates that intensifying ETTCs are associated with deep upper-level troughs to their northwest, intense ridge building to their northeast, and strong updrafts to their north associated with vorticity advection and warm-air advection. These results statistically support the findings of previous studies. Furthermore, an analysis using a time filter demonstrates the relationship between planetary-scale environments and synoptic-scale dynamics in the upper levels. The high PV to the northwest of ETTCs is attributed not only to eastward-moving troughs, but also to the environmental PV. The low PV to the northeast of ETTCs results from the negative PV formation associated with ridge building, which almost cancels the environmental PV. Thus, the environmental PV at relatively high latitudes enhances the intensity of positive PV to the northwest of ETTCs, and increases the upper limit of the magnitude of ridge building to the northeast.
\end{abstract}

KEYWORDS: North Pacific Ocean; Extratropical cyclones; Storm environments; Tropical cyclones; Reanalysis data

\section{Introduction}

Many tropical cyclones (TCs) move to baroclinic environments at the midlatitudes, where they change into extratropical cyclones through the extratropical transition (ET) process (Jones et al. 2003; Evans et al. 2017; Keller et al. 2019). During this process, the TCs acquire asymmetric distribution of intense wind and precipitation, and they cause disasters in a different manner from typical TCs in the tropics. Whereas TCs usually weaken in midlatitude environments owing to cool sea surface temperature (SST) and strong vertical wind shear, TCs that complete ET (ETTCs) sometimes reintensify posing additional threats to midlatitude countries.

Previous case studies have proposed that reintensifying ETTCs were affected by various large-scale conditions that range from synoptic-scale disturbances to planetary-scale environments. Synoptic-scale disturbances include upper-level

๑ Denotes content that is immediately available upon publication as open access.

Supplemental information related to this paper is available at the Journals Online website: https://doi.org/10.1175/JCLI-D-200013.s1.

Corresponding author: Wataru Yanase, wtryanase@gmail.com transient troughs and ETTCs themselves (Thorncroft and Jones 2000; McTaggart-Cowan et al. 2001; Agustí-Panareda et al. 2004, 2005; Grams et al. 2013; Griffin and Bosart 2014). Klein et al. (2002) proposed three synoptic-scale conditions that diagnose the development of ETTCs: upper-level divergence, midlevel vorticity advection, and low-level temperature advection. Evans and Prater-Mayes (2004) also showed that the reintensification of Hurricane Irene (1999) was associated with midlevel vorticity advection and low-level temperature advection. On the other hand, planetary-scale environments are larger-scale conditions in which ETTCs develop. AgustíPanareda et al. (2005) showed that Hurricane Irene (1999) in a cyclonic-shear environment became more intense than TC Lili (1996) in an anticyclonic-shear environment after ET. Thorncroft and Jones (2000) reported that Hurricane Iris (1995) maintained a warm-core structure and developed significantly over warm sea surfaces, whereas Hurricane Felix (1995) did not develop over cold sea surfaces at a higher latitude; Iris also moved to the north of the jet axis, which may have influenced its development.

As the large-scale conditions responsible for ETTC reintensification vary from case to case, it is useful to assess them statistically. Hart and Evans (2001) showed that ETTC development over the North Atlantic Ocean is associated with the combination of an environment supporting tropical development (large maximum potential intensity; Bister and Emanuel 2002) and an environment supporting extratropical 
development (Eady growth rate; Hoskins and Valdes 1990). In a composite analysis of ETTCs over the North Atlantic Ocean, Hart et al. (2006) showed that upper-level troughs to the northwest of reintensifying ETTCs are oriented in a northwest-southeast direction, whereas those northwest of dissipating ETTCs are oriented in northeast-southwest; they also showed that reintensifying ETTCs are associated with high SSTs and steep SST gradients. Li and Xu (2015) reported that among ETTCs that made landfall in China, reintensifying ETTCs were associated with strong upper-level divergence under the influence of upper-level troughs and large generation of kinetic energy.

Recent studies on ETTCs have paid much attention to their interactions with midlatitude flow in the upper levels (Keller et al. 2019); diabatically driven outflow of an ETTC causes negative potential vorticity (PV) advection, enhances a ridge and a jet streak on the east side of the ETTC, and then initiates a Rossby wave packet (e.g., Grams and Archambault 2016; Riboldi et al. 2018). Negative PV advection also modify the eastward propagation of an upper-level trough (AgustíPanareda et al. 2004; Riboldi et al. 2019). Although most of these studies focused mainly on the upper-level dynamics of the Rossby waves, the dynamics may be also related to the development of surface cyclones (Archambault et al. 2013; Riboldi et al. 2018, 2019).

In this paper, we statistically examine the large-scale conditions responsible for reintensification of ETTCs in the western North Pacific Ocean. Although several statistical studies of ETTCs in the western North Pacific have analyzed their seasonality (Kitabatake 2011), large-scale circulation (Harr et al. 2000), and extratropical flow response (Archambault et al. 2013, 2015; Quinting and Jones 2016; Riboldi et al. 2018, 2019), few statistical studies have focused on the reintensification of ETTCs. In this paper, we address the following three questions.

- Which large-scale conditions are responsible for ETTC reintensification statistically? In addition, as for synoptic-scale dynamics, which segment of the ETTC is significantly affected?

- Which season and region provide favorable planetary-scale environments for ETTC reintensification climatologically? While colder seasons and higher latitudes support extratropical or baroclinic development, warmer seasons and lower latitudes support tropical or diabatic development. The balance between these two environments makes the problem complicated for ETTCs compared to typical TCs and extratropical cyclones.

- Are there any relationships between planetary-scale environments and synoptic-scale dynamics? To elucidate this point, we use a time filter to separate planetary-scale and synoptic-scale fields.

Section 2 of this paper describes the dataset and methodology used for the statistics of ETTC development. Section 3 explores the climatology of the environmental fields for ETTCs, and section 4 presents the results of composite analysis. Section 5 discusses the relationship between the different large-scale conditions analyzed in this study and previous studies. Section 6 summarizes the important large-scale conditions responsible for the ETTC reintensification.

\section{Methodology}

\section{a. ETTC dataset}

This study analyzes the best track data product from the Japan Meteorological Agency (JMA) in the satellite era (1979-2018). The JMA best track record provides at least 6-hourly $(0000,0600,1200$, and 1800 UTC) information on the longitudes, latitudes, and central pressure $\left(p_{c}\right)$ of TCs. The ET completion time is defined as the time when the JMA best track record first categorizes a cyclone as an extratropical cyclone. The JMA best track record has been used for previous studies of ETTCs or recurving TCs in the midlatitude western North Pacific (Archambault et al. 2013; Li and Xu 2015), because it contains information after ET completion. Previous studies have confirmed that the ETTCs in the JMA best track record agree well with ETTCs that are objectively classified using atmospheric reanalysis data (Kitabatake 2011; Bieli et al. 2019).

The JMA best track data records 488 ETTC cases during the period 1979-2018. We discarded 110 cases that weakened to tropical depression intensity (maximum sustained surface wind $<34 \mathrm{kt} ; 1 \mathrm{kt} \approx 0.51 \mathrm{~m} \mathrm{~s}^{-1}$ ) before their ET completion. Then we selected intensifying (INT), dissipating (DIS), and neutral (NEU) classes from the remaining 378 cases based on the change in $p_{c}$ over $6 \mathrm{~h}\left[\Delta p_{c}(t) \equiv p_{c}(t+6 \mathrm{~h})-p_{c}(t)\right]$. Because it is not easy to determine the ET completion time with an accuracy of several hours (Kitabatake 2011; Bieli et al. 2019), we examined $\Delta p_{c}$ not only at the ET completion time but also for the subsequent $24 \mathrm{~h}$. Note that the ETTCs were not analyzed more than $24 \mathrm{~h}$ after the ET completion time as they may already lost their tropical characteristics. An ETTC was classified as INT if $\Delta p_{c} \leq-6 \mathrm{hPa}$ at least once within the $24 \mathrm{~h}$, and as DIS if $\Delta p_{c} \geq 6 \mathrm{hPa}$. An ETTC was classified as NEU if it survived the $24 \mathrm{~h}$ and its absolute value of $\Delta p_{c}$ did not exceed $2 \mathrm{hPa}$ during the $24 \mathrm{~h}$. To obtain robust results, this paper focuses mainly on the difference between the INT and DIS classes, which is characterized by the large pressure change, and shows the NEU class only for reference.

The key time $\left(T_{0}\right)$ for INT and DIS was defined as the time when $\Delta p_{c}$ first satisfied the 6-hPa thresholds. On average, $T_{0}$ for INT and DIS occurs 9.3 and $4.3 \mathrm{~h}$ after the ET completion, respectively; therefore, $T_{0}$ for NEU was defined at $6 \mathrm{~h}$ after the ET completion so that the time of $T_{0}$ relative to the ET completion becomes nearly the same between the three classes. We rejected NEU cases that were weak $\left(p_{c}>990 \mathrm{hPa}\right)$ at the key time, so that the intensity are also nearly the same between the classes. Because it is difficult to interpret the development mechanism of ETTCs over land, we only analyze the ETTCs that were over the ocean at the key time.

These classification and thresholds resulted in 40 INT cases, 46 DIS cases, and 26 NEU cases. Although the numbers of these samples are small compared to the 488 ETTC cases in total, they are sufficient to obtain statistically significant results. Figure 1 shows the time series of $p_{c}$ for the INT, NEU, and DIS classes from $24 \mathrm{~h}$ before to $24 \mathrm{~h}$ after $T_{0}$. Note that ETTCs at $T_{0}$ are extratropical cyclones by definition, whereas ETTCs before $T_{0}$ are either TCs or extratropical cyclones. 


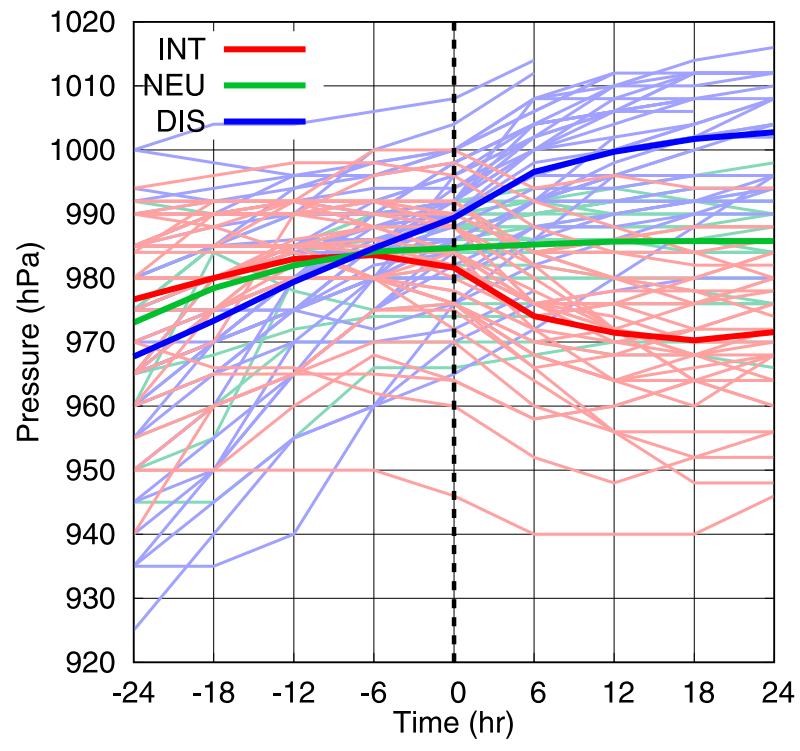

FIG. 1. Time series of the minimum pressure for the INT (red), NEU (green), and DIS (blue) cases for the $24 \mathrm{~h}$ before and after $T_{0}$. The thin curves represent individual ETTCs, and the thick curves are the means for each ETTC class.

\section{b. Large-scale fields}

The large-scale conditions around the ETTCs were analyzed using the 6-hourly JRA-55 (Kobayashi et al. 2015). JRA-55 uses a global atmospheric model, with a TL319 spectral horizontal resolution $(\sim 60 \mathrm{~km})$ and 60 vertical levels, and the JMA's four-dimensional variational data assimilation (4DVar). The Centennial In Situ Observation-Based Estimates of the Variability of SSTs and Marine Meteorological Variables (COBE; Ishii et al. 2005) datasets with a $1^{\circ}$ resolution were used for the lower boundary conditions. Because we were interested in the large-scale conditions around the ETTCs rather than the internal mesoscale structure of the ETTCs, the horizontal resolution of JRA-55 was sufficient for our purpose.

To elucidate different time scales of the large-scale conditions, we used the Lanczos filter with 30-day cutoff period and 120-day data window. We separated the original data (total field) into the filtered data (mean field) and the difference between the original and filtered data (eddy field) (i.e., the total field is the sum of the mean field and the eddy field). The mean field represents planetary-scale environments for ETTCs, such as SST and baroclinicity, whereas the eddy field represents synoptic-scale dynamics, such as ETTCs themselves and upper-level disturbances.

\section{Climatology and environmental fields}

\section{a. Seasonal and geographical distribution}

The seasonal cycle of ETTC activity in our dataset (Fig. 2) shows that ETTCs were most frequent in September, which is consistent with previous studies of ETTCs in the western North Pacific (Kitabatake 2011) and the North Atlantic Ocean (Hart and Evans 2001). The most active season for the INT class (September-October) was earlier than that for the DIS class

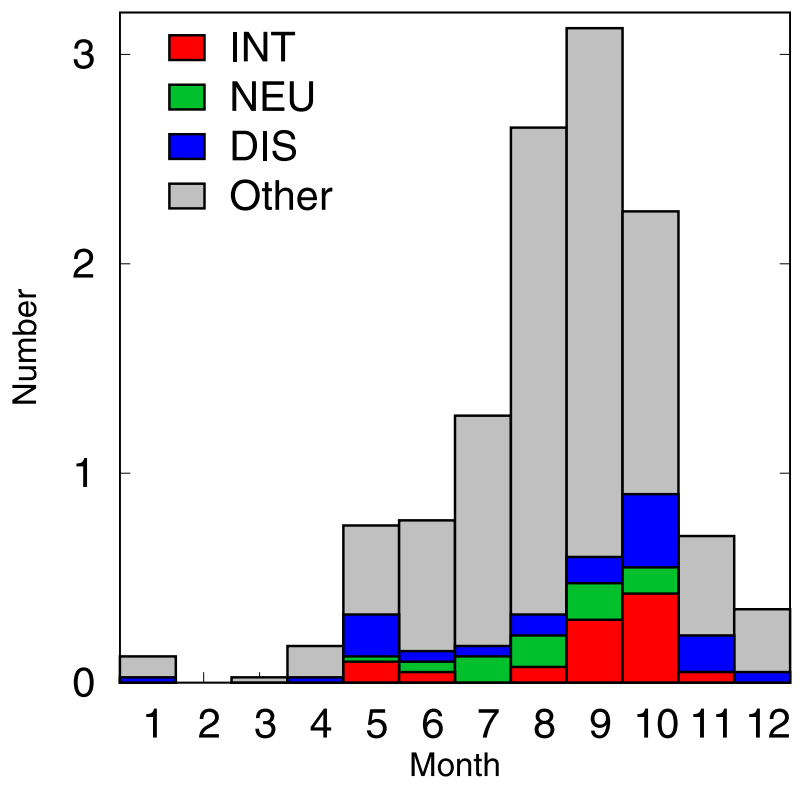

FIG. 2. Annual number of ETTCs by month (date of ET completion) for the INT (red), NEU (green), DIS (blue), and other ETTC (gray) cases in the 40-yr JMA dataset.

(October-November). The NEU class did not have a prominent peak, and its seasonality was not simply intermediate between the INT and DIS classes.

The tracks of the ETTC centers for the $24 \mathrm{~h}$ before and after $T_{0}$ are shown in Fig. 3. The mean location for the INT class was

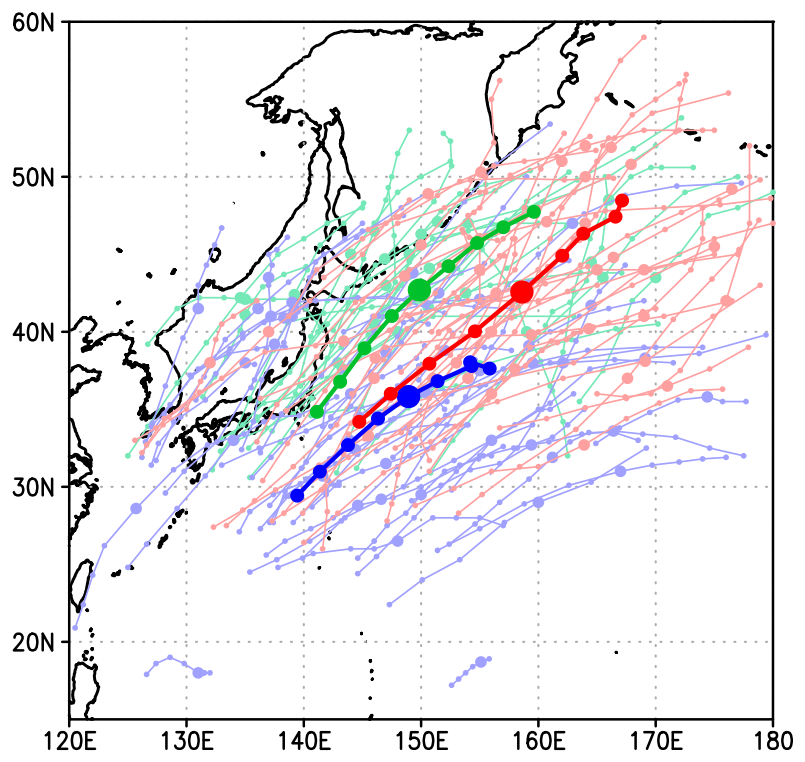

FIG. 3. Map of the western North Pacific showing tracks of ETTCs during the $24 \mathrm{~h}$ before and after $T_{0}$ for the INT (red), NEU (green), and DIS (blue) cases. The thin curves represent the individual ETTCs, and the thick curves are the means for each ETTC class. The circles indicate 6-hourly locations of ETTCs with large circles at $T_{0}$. 
(a) Sea surface temperature

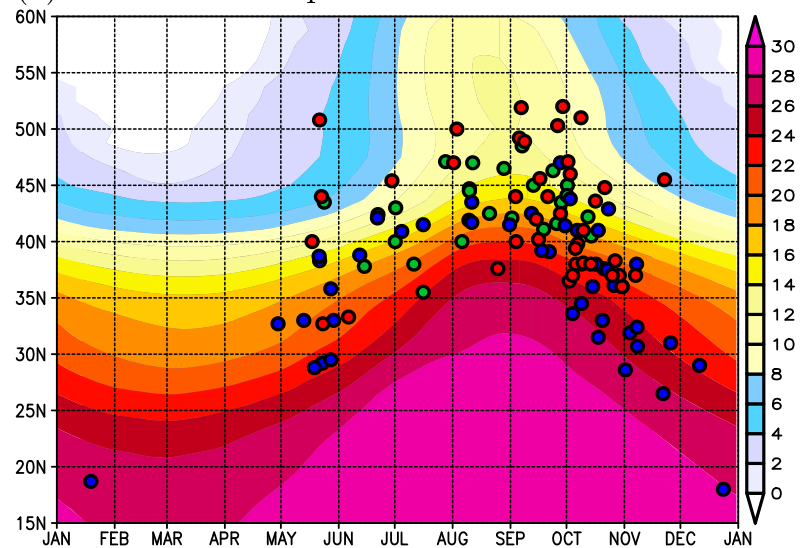

(c) EPT gradient at $850 \mathrm{hPa}$

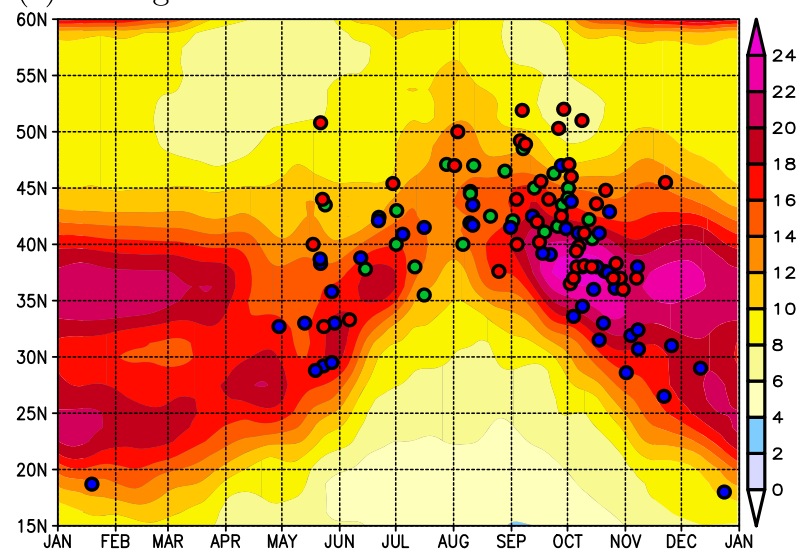

(e) PV at $330 \mathrm{~K}$

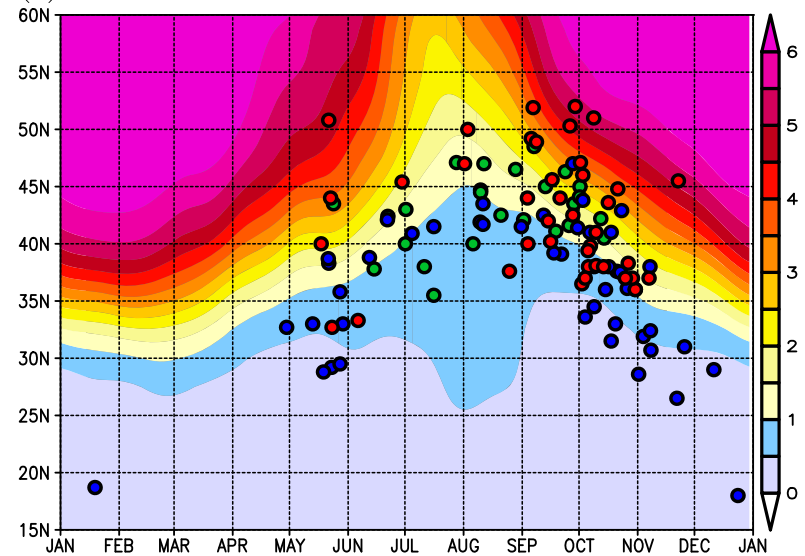

(b) Eady growth rate

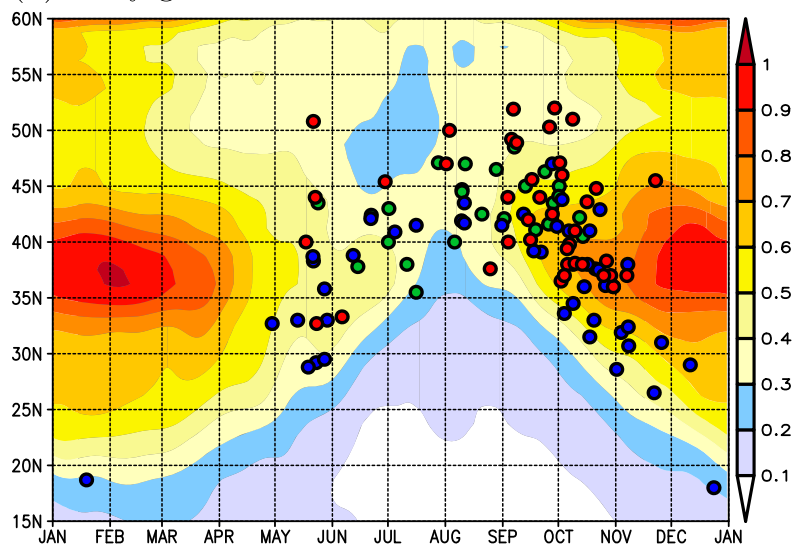

(d) Relative vorticity and zonal wind at $500 \mathrm{hPa}$

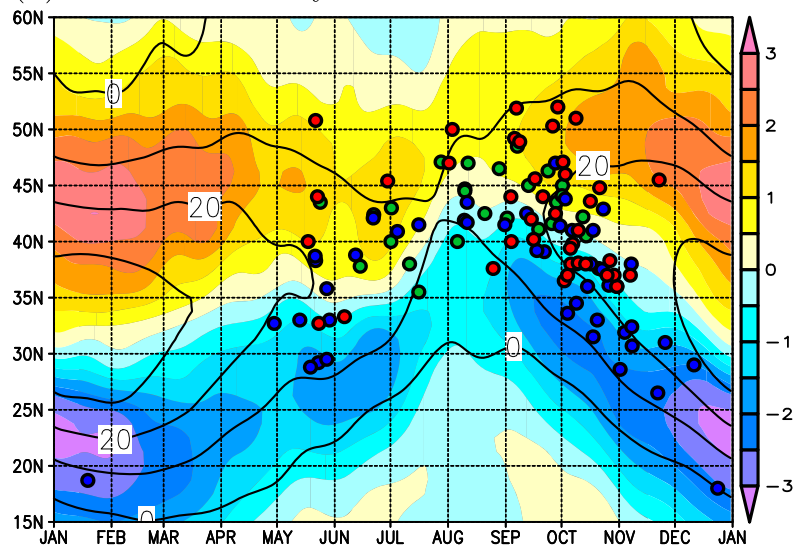

(f) PV gradient at $330 \mathrm{~K}$

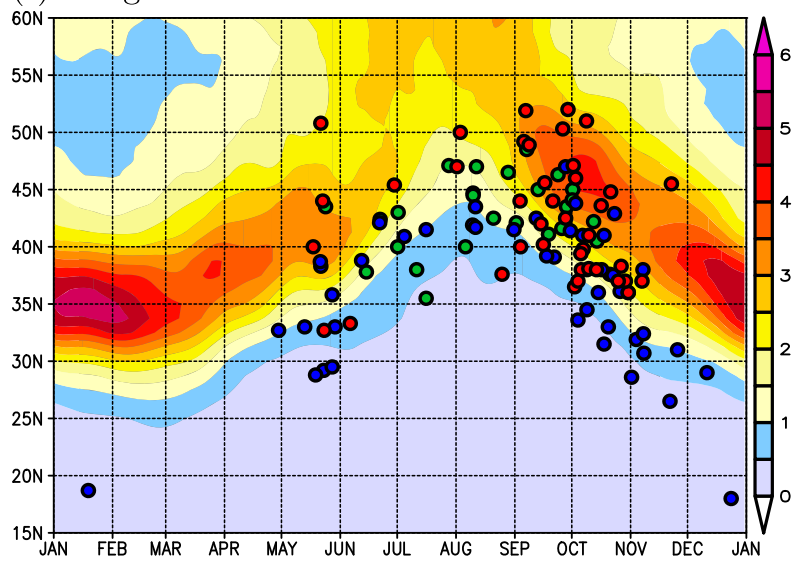

FIG. 4. Seasonal and meridional distribution of climatological fields averaged between $140^{\circ}$ and $170^{\circ} \mathrm{E}$ : (a) SST $\left({ }^{\circ} \mathrm{C}\right)$, (b) Eady growth rate at $850 \mathrm{hPa}\left(\right.$ day $\left.^{-1}\right)$, (c) EPT gradient at $850 \mathrm{hPa}\left(10^{-6} \mathrm{~K} \mathrm{~m}^{-1}\right)$, (d) relative vorticity (shading; $10^{-5} \mathrm{~s}^{-1}$ ) and zonal wind at $500 \mathrm{hPa}$ (contours at $5 \mathrm{~m} \mathrm{~s}^{-1}$ interval), (e) PV at the $330 \mathrm{~K}$ isentropic surface (PVU), and (f) horizontal PV gradient at the $330 \mathrm{~K}$ isentropic surface $\left(10^{-6} \mathrm{PVU} \mathrm{m}^{-1}\right)$. Colored circles indicate the time and latitude of ETTCs at $T_{0}$ for the INT (red), NEU (green), and DIS (blue) cases.

farther north and east than that for the DIS class. Again, the mean location for the NEU class was not simply intermediate between those for the INT and DIS classes; its mean longitude was close to that for the DIS class, whereas its mean latitude was close to that for the INT class.

\section{b. Environmental fields for the ETTCs}

To assess the environments that may affect ETTC development, Fig. 4 shows seasonal and meridional distribution of climatological fields for six environmental factors with our population of ETTCs superimposed. The climatological fields 
are obtained by 40-yr average of the mean fields. Whereas the climatological field clearly shows the seasonality of the environmental field, it smooths out the modulation of the environmental field associated with intraseasonal and interannual variability. Therefore, to examine the environmental fields for the individual ETTCs more precisely, Fig. 5 and Table 1 show the average of the mean fields around the ETTC centers at $T_{0}$ for each class. In addition, Fig. S1 in the online supplemental material shows meridional distribution of the environmental fields relative to the ETTC centers. An environmental field is considered to be a good indicator of ETTC development, 1) if it is significantly different between the INT and DIS classes, 2) if it changes monotonically from the INT class through the NEU class to the DIS class, and 3) if it explains some development mechanisms.

High SST is known to be a favorable condition for the development of TCs, which reaches its peak in August and September (Fig. 4a). Although the INT cases occurred in the relatively high SST season (early autumn) compared to the DIS cases (late autumn) on average, they occurred at relatively high latitudes with low SST. As a result, the INT cases are associated with lower SST than the DIS cases (Fig. 5a, Fig. S1a). Maximum potential intensity is a more sophisticated environmental factor for TCs that is based on a theoretical treatment of TC development mechanisms, which considers not only SST but also the stability of the atmosphere (Bister and Emanuel 2002). The maximum potential intensity had a seasonality similar to that of SST (not shown), and consequently was smaller for the INT cases than that for the DIS cases (Table 1). Thus, neither SST nor maximum potential intensity explain ETTC development in a climatological sense, although they are favorable for TC development. This result does not necessarily mean that SST and maximum potential intensity are unfavorable for ETTC development, because their influences may be counteracted by other factors.

The Eady growth rate, an environmental factor favoring the baroclinic development of extratropical cyclones (Lindzen and Farrell 1980; Hoskins and Valdes 1990), is large in cold seasons. Figure $4 \mathrm{~b}$ shows that most of the ETTCs occurred in environments with the Eady growth rate exceeding 0.3 day $^{-1}$. The INT cases occurred in a season when the Eady growth rate was smaller than it was for the DIS cases. However, the relatively high latitudes of the INT cases partly compensated for this seasonal difference. As a result, the Eady growth rates were comparable for the INT and DIS cases (Fig. 5b, Fig. S1b), though the Eady growth rate of the former was slightly smaller than that of the latter. The Eady growth rate for the NEU cases was the smallest of the three classes, because the NEU cases tended to favor warm seasons. We also examined whether the INT cases experienced environment with larger Eady growth rate than the DIS cases during the northward motion before the key time (Fig. 3). While the Eady growth rate was slightly larger for the INT cases than for the DIS cases at $T_{0}-12 \mathrm{~h}$ and $T_{0}-24 \mathrm{~h}$ (Table 1 ), the difference was not significant. Thus, the Eady growth rate does not seem to be a good indicator of ETTC development, although it is considered to be necessary for the ET process itself. Because moist process may enhance the baroclinic process, we examined horizontal gradient of

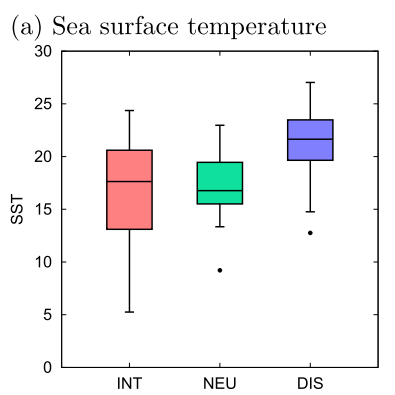

(c) EPT gradient at $850 \mathrm{hPa}$

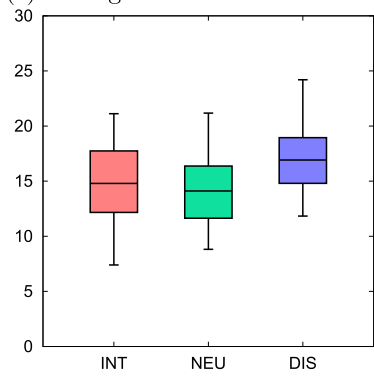

(e) PV at $330 \mathrm{~K}$

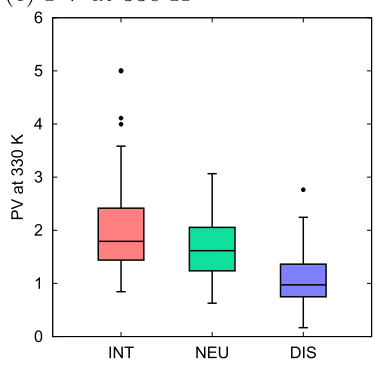

(b) Eady growth rate

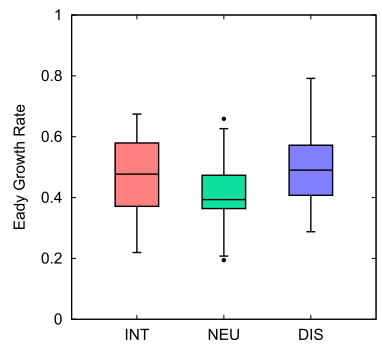

(d) Relative vorticity at $500 \mathrm{hPa}$

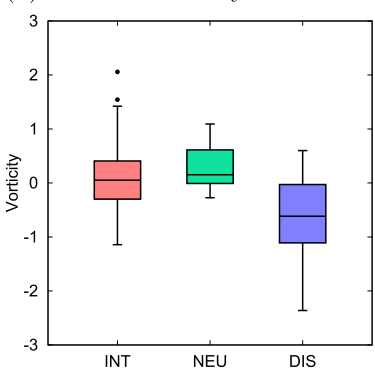

(f) PV gradient at $330 \mathrm{~K}$

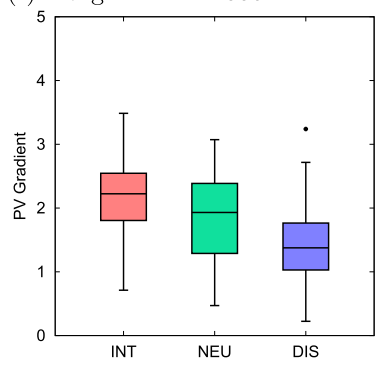

FIG. 5. Box-and-whisker plots of environmental fields at $T_{0}$ for the INT (red), NEU (green), and DIS (blue) cases: (a) SST $\left({ }^{\circ} \mathrm{C}\right)$, (b) Eady growth rate at $850 \mathrm{hPa}\left(\right.$ day $\left.^{-1}\right)$, (c) EPT gradient at $850 \mathrm{hPa}\left(10^{-6} \mathrm{~K} \mathrm{~m}^{-1}\right)$, (d) relative vorticity at $500 \mathrm{hPa}\left(10^{-5} \mathrm{~s}^{-1}\right)$, (e) PV at the $330 \mathrm{~K}$ isentropic surface (PVU), and (f) horizontal PV gradient at the $330 \mathrm{~K}$ isentropic surface $\left(10^{-6} \mathrm{PVU} \mathrm{m}^{-1}\right)$. The variables are averaged over a $10^{\circ}$ radius from the ETTC centers. The boxes indicate interquartile ranges with horizontal lines at the median values, the whiskers extend to the 1.5 times the interquartile ranges, and the points lie outside these ranges.

equivalent potential temperature (EPT) at $850 \mathrm{hPa}$. While the EPT gradient had a little different distribution from the Eady growth rate (Fig. 4c), it was still smaller for the INT cases than for the DIS cases (Fig. 5c).

In the middle level, the zonal wind showed characteristics similar to the Eady growth rate (Fig. 4d), except that its magnitude was greater for the INT than for the DIS cases (Table 1). The INT cases were located near the axis of the westerly jet stream, whereas the DIS cases were south of the axis (Fig. 4d). As a consequence, the midlevel vorticity was larger for the INT cases than the DIS cases (Figs. 4d, 5d). This characteristic is discussed further in section 5 .

As baroclinic development is associated with an interaction between lower-level and upper-level disturbances, upper-level environmental fields may play important roles. The $330 \mathrm{~K}$ isentropic surface, which corresponds to $200-400 \mathrm{hPa}$ at the 
TABLE 1. Indices of the planetary-scale environments and synoptic-scale dynamics. Variable names, units (in parentheses), and relevant figures (in square brackets) are listed in column 1. Mean and standard deviation (in parentheses) for the INT, NEU, and DIS cases are listed in columns 2,3, and 4, respectively. Differences between the INT and NEU cases (I-N), between the NEU and DIS cases (N-D), and between the INT and DIS cases (I-D) are listed in columns 5, 6, and 7, respectively, where those in boldface denote a significance level of 0.05 based on Welch's $t$ test. The indices of the planetary-scale environments are averages over a $10^{\circ}$ radius from the ETTC centers at $T_{0}$ with a few exceptions.

\begin{tabular}{|c|c|c|c|c|c|c|}
\hline & INT & NEU & DIS & $\mathrm{I}-\mathrm{N}$ & N-D & $\mathrm{I}-\mathrm{D}$ \\
\hline \multicolumn{7}{|c|}{ Planetary-scale environments } \\
\hline Sea surface temperature $\left({ }^{\circ} \mathrm{C}\right)$ [Fig. $\left.5 \mathrm{a}\right]$ & $16.8(4.7)$ & $17.4(3.2)$ & $21.2(3.4)$ & -0.6 & -3.9 & -4.5 \\
\hline Maximum potential intensity $\left(\mathrm{m} \mathrm{s}^{-1}\right)$ & $17.6(11.9)$ & $12.8(9.9)$ & $27.1(14.4)$ & 4.7 & -14.3 & -9.5 \\
\hline $\begin{array}{l}\text { Eady growth rate at } T_{0} \text { at } 850 \mathrm{hPa}\left(\text { day }^{-1}\right) \\
\text { [Fig. 5b] }\end{array}$ & $0.48(0.12)$ & $0.42(0.12)$ & $0.49(0.1)$ & 0.06 & -0.07 & -0.01 \\
\hline Eady growth rate at $T_{0}-12 \mathrm{~h}\left(\mathrm{day}^{-1}\right)$ & $0.47(0.12)$ & $0.40(0.11)$ & $0.45(0.10)$ & 0.07 & -0.04 & 0.02 \\
\hline Eady growth rate at $T_{0}-24 \mathrm{~h}\left(\right.$ day $\left.^{1}\right)$ & $0.42(0.12)$ & $0.35(0.10)$ & $0.38(0.09)$ & 0.08 & -0.04 & 0.04 \\
\hline $\begin{array}{l}\text { EPT gradient at } 850 \mathrm{hPa}\left(10^{-6} \mathrm{~K} \mathrm{~m}^{-1}\right) \\
\quad \text { [Fig. } 5 \mathrm{c}]\end{array}$ & $14.7(3.5)$ & $14.3(3.3)$ & $17.0(2.8)$ & 0.35 & -2.62 & -2.23 \\
\hline Zonal wind at $500 \mathrm{hPa}\left(\mathrm{m} \mathrm{s}^{-1}\right)$ & $17.1(4.4)$ & $13.4(4.7)$ & $14.9(4.7)$ & 3.7 & -1.5 & 2.2 \\
\hline Vorticity at $500 \mathrm{hPa}\left(10^{-5} \mathrm{~s}^{-1}\right)[$ Fig. $5 \mathrm{~d}]$ & $0.16(0.69)$ & $0.26(0.41)$ & $-0.61(0.72)$ & -0.10 & 0.87 & 0.77 \\
\hline $\mathrm{PV}$ at $330 \mathrm{~K}$ (PVU) [Figs. 5e, 11b, 11c] & $2.10(1.04)$ & $1.67(0.65)$ & $1.12(0.58)$ & 0.43 & 0.55 & 0.98 \\
\hline $\mathrm{PV}$ at $350 \mathrm{~K}$ (PVU) & $3.85(1.35)$ & $3.66(0.87)$ & $2.30(1.07)$ & 0.19 & 1.36 & 1.55 \\
\hline PV gradient at $330 \mathrm{~K}\left(10^{-6} \mathrm{PVU} \mathrm{m}^{-1}\right)$ [Fig. $\left.5 \mathrm{f}\right]$ & $2.19(0.62)$ & $1.82(0.75)$ & $1.48(0.64)$ & 0.37 & 0.34 & 0.71 \\
\hline $\mathrm{PV}$ gradient at $350 \mathrm{~K}\left(10^{-6} \mathrm{PVU} \mathrm{m}^{-1}\right)$ & $3.09(0.50)$ & $3.34(0.50)$ & $2.68(0.84)$ & -0.25 & 0.66 & 0.41 \\
\hline \multicolumn{7}{|c|}{ Synoptic-scale dynamics } \\
\hline PVnw at $T_{0}(\mathrm{PVU})$ & $5.66(1.98)$ & $4.04(2.33)$ & $3.33(2.33)$ & 1.62 & 0.71 & 2.33 \\
\hline PVnw at $T_{0}-12 \mathrm{~h}$ (PVU) [Fig. 9a] & $5.11(1.87)$ & $3.40(1.73)$ & $3.07(1.49)$ & 1.71 & 034 & 2.05 \\
\hline PVEnw at $T_{0}$ (PVU) [Fig. 11b] & $0.49(1.39)$ & $0.05(1.56)$ & $-0.56(1.35)$ & 0.44 & 0.61 & 1.05 \\
\hline PVEnw at $T_{0}-12 \mathrm{~h}$ (PVU) [Figs. 9b, 11a] & $0.79(1.46)$ & $0.10(1.18)$ & $-0.23(1.24)$ & 0.69 & 0.33 & 1.01 \\
\hline PVEne at $T_{0}$ (PVU) [Fig. 11c] & $-2.64(1.25)$ & $-2.04(1.39)$ & $-1.14(1.36)$ & -0.59 & -0.90 & -1.49 \\
\hline PVEne at $T_{0}-12 \mathrm{~h}$ (PVU) (Fig. 9c) & $-1.76(1.53)$ & $-1.25(1.01)$ & $-0.80(0.85)$ & -0.51 & -0.45 & -0.96 \\
\hline Wne at $T_{0}\left(\mathrm{hPa} \mathrm{h}^{-1}\right)$ & $0.38(3.80)$ & $1.63(3.50)$ & $3.20(6.07)$ & -1.26 & -1.57 & -2.82 \\
\hline Wne at $T_{0}-12 \mathrm{~h}\left(\mathrm{hPa} \mathrm{h}^{-1}\right)$ [Figs. 9d, 11a] & $-1.62(4.57)$ & $0.70(4.16)$ & $2.51(5.36)$ & -2.32 & -1.81 & -4.13 \\
\hline
\end{tabular}

midlatitudes, has been analyzed in previous studies of the interaction between the TCs and midlatitude flow (Quinting and Jones 2016; Riboldi et al. 2018). Figure 4e shows that the PV at $330 \mathrm{~K}$ was high at high latitudes and in cold seasons, and that the INT cases occurred in the high PV environment at relatively high latitudes. Figure 5e confirms that the development of ETTCs is in good agreement with the PV at $330 \mathrm{~K}$ (i.e., the PV was the highest for the INT cases and lowest for the DIS cases). The horizontal gradient of PV may be also important for Rossby wave dynamics in the upper levels and baroclinic development of ETTCs. The PV gradient was steepest around the midlatitudes (Fig. 4f), where PV increases rapidly with latitude (Fig. 4e). The INT cases were near the latitude of the maximum PV gradient, whereas the DIS cases were south of it (Fig. 4f). Also note that the PV gradient for the NEU cases was smaller than that for the INT cases because of the warm season. On the whole, the development of ETTCs is in good agreement with PV gradient (Fig. 5f). Because previous studies analyzed PV at different levels (Quinting and Jones 2016; Riboldi et al. 2018), we also examined the PV at the $350 \mathrm{~K}$ isentropic surface (Table 1); the PV at $350 \mathrm{~K}$ is also a good indicator of ETTC development, whereas the PV gradient at $350 \mathrm{~K}$ did not change monotonically (the gradient was largest for the NEU cases).

The results in this section imply that the upper-level PV is a good indicator of ETTC development. These are explored further in the remainder of this study.

\section{Composite analysis}

In this section we compare composite fields between the different ETTC classes to investigate synoptic-scale processes, including the ETTCs themselves and upper-level disturbances, and their relationship with environmental fields.

\section{a. Lower and middle levels}

The lower and middle level fields are briefly described as basic information. Composite fields of geopotential height at 500 and $850 \mathrm{hPa}$ for the INT and DIS cases and the difference between them are presented in Figs. 6a-f. The geopotential height at $850 \mathrm{hPa}$ at the ETTC center is lower in the INT cases than that in the DIS cases, simply because the ETTCs in the INT class have deepened slightly by $T_{0}$ (Fig. 1). The low pressure system of the INT cases extends northwest from the ETTC center, whereas that of the DIS cases extends northeast. These patterns are similar to the northwest and northeast circulation patterns of Harr et al. (2000, their Fig. 1). At $500 \mathrm{hPa}$, a trough to the northwest of the ETTC center for the INT cases is markedly oriented in a northwest-southeast direction, which is consistent with Hart et al. (2006, their Fig. 12). These characteristics are discussed in section $5 \mathrm{~b}$.

As warm and moist air in the lower levels can affect diabatic processes within updrafts, the composite fields of EPT at $850 \mathrm{hPa}$ are compared in Figs. $6 \mathrm{~g}-\mathrm{i}$. A region of high EPT lies slightly east of the ETTC center in both the INT and DIS cases 
(a) INT: Height at $500 \mathrm{hPa}$

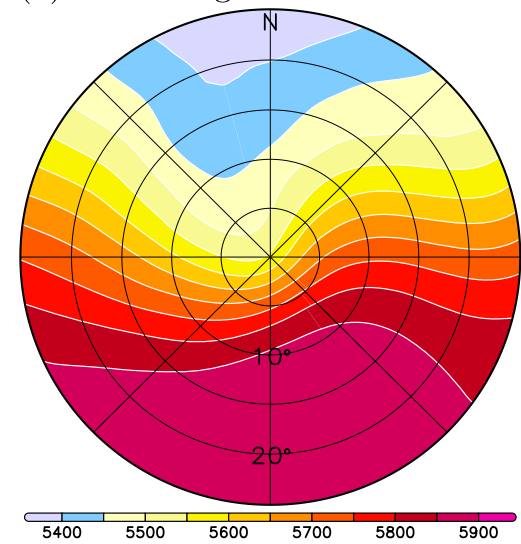

(d) INT: Height at $850 \mathrm{hPa}$

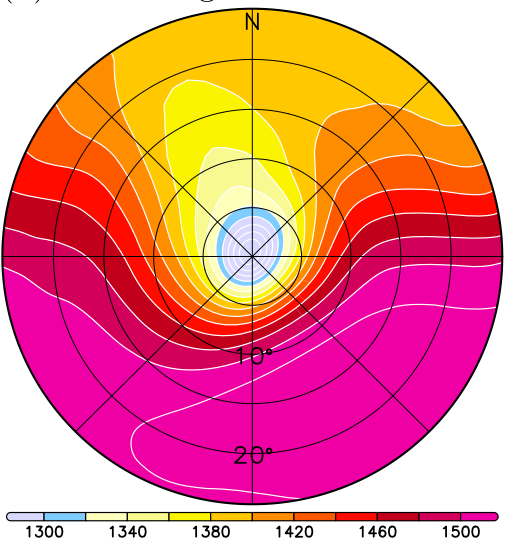

(g) INT: E.P.T. at $850 \mathrm{hPa}$

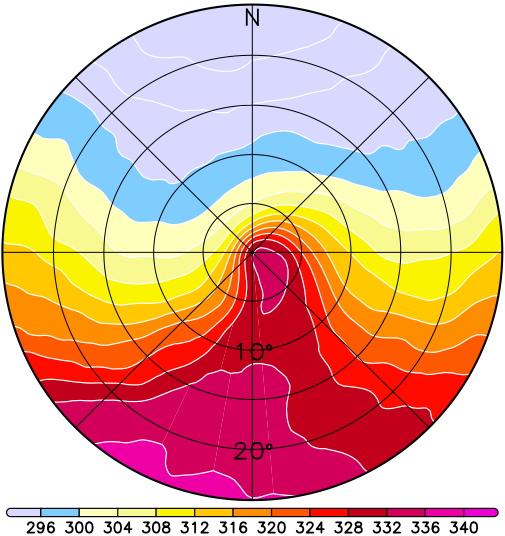

(b) DIS: Height at $500 \mathrm{hPa}$

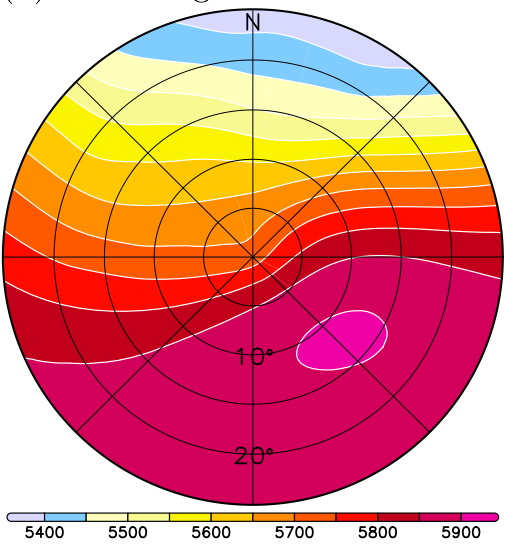

(e) DIS: Height at $850 \mathrm{hPa}$

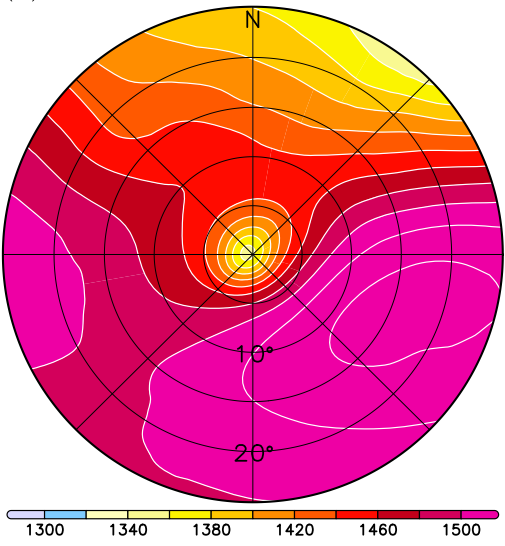

(h) DIS: E.P.T. at $850 \mathrm{hPa}$

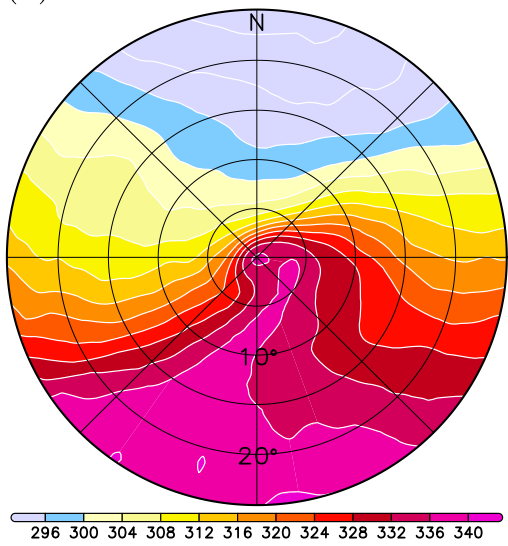

(c) I-D: Height at $500 \mathrm{hPa}$

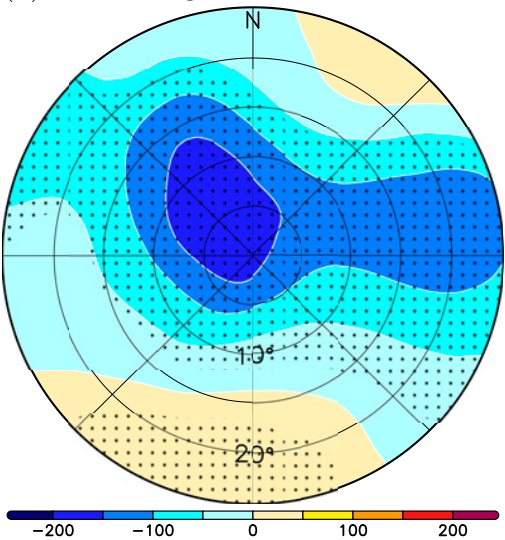

(f) I-D: Height at $850 \mathrm{hPa}$

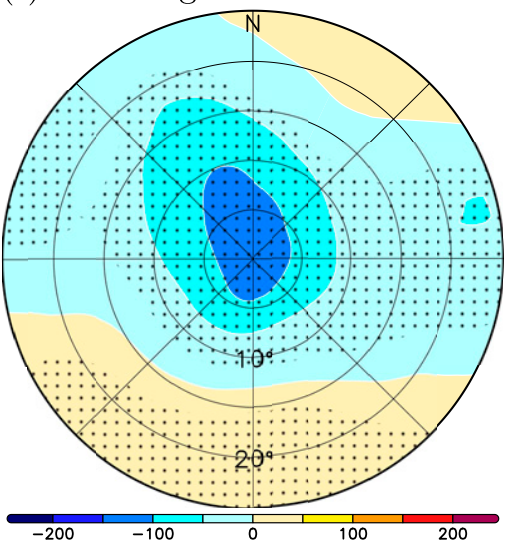

(i) I-D: E.P.T. at $850 \mathrm{hPa}$

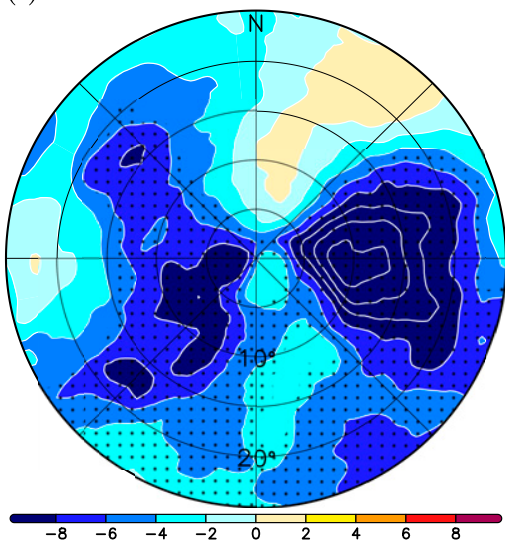

FIG. 6. Composite fields relative to the ETTC centers at $T_{0}$ for (left) INT, (center) DIS, and (right) their difference (INT minus DIS). (a)-(c) Geopotential height at $500 \mathrm{hPa}(\mathrm{m})$. (d)-(f) Geopotential height at $850 \mathrm{hPa}(\mathrm{m})$. (g)-(i) EPT at $850 \mathrm{hPa}(\mathrm{K})$. The radial rings denote the distance from the ETTC center in $5^{\circ}$ increments (approximately $550 \mathrm{~km}$ ); north is up. The stippled areas in the right column denote a significance level of 0.05 based on Welch's $t$ test.

(Figs. 6g,h). This warm sector is narrower in the INT cases than that in the DIS cases, which may result from the larger environmental vorticity (Figs. 4d, 5d) as demonstrated by Wernli et al. (1998, their Fig. 4). The difference between the two cases is negative around the ETTCs except the northeast segment (Fig. 6i), because the INT cases were at relatively high latitudes.
More precisely, both temperature and specific humidity at $850 \mathrm{hPa}$ are lower in the INT cases than in the DIS cases (not shown). Thus, the planetary-scale environmental fields are less favorable for diabatic processes in the INT cases than in the DIS cases, whereas northeast of the ETTCs, synoptic-scale processes create an environment more favorable for diabatic processes. 
(a) INT: PV

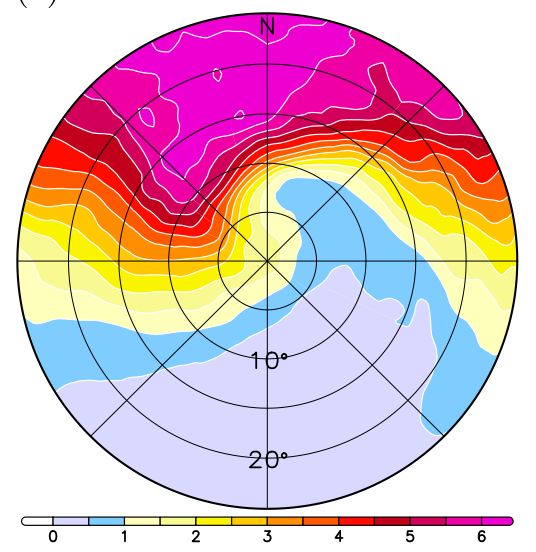

(d) INT: Mean PV

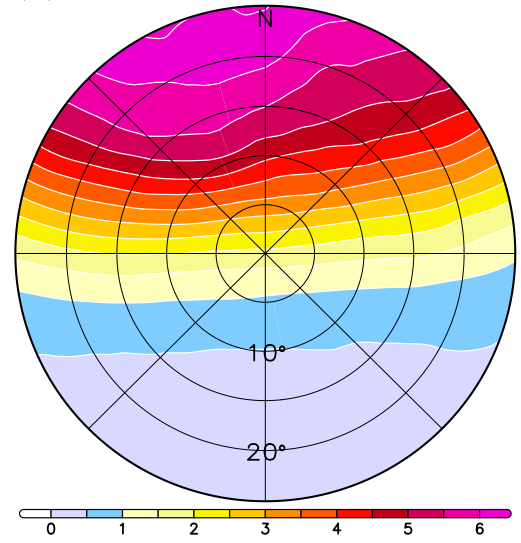

(g) INT: Eddy PV

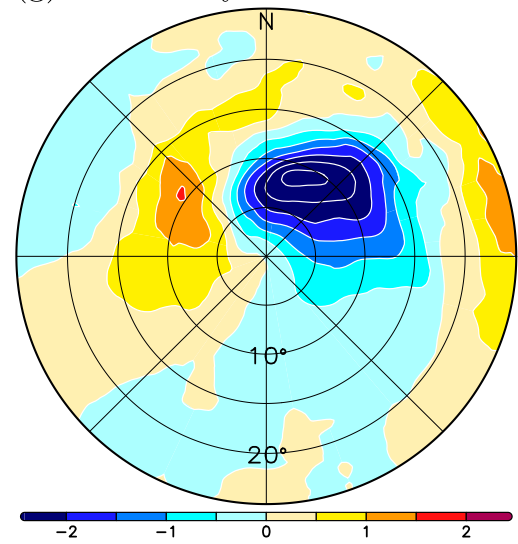

(b) DIS: PV

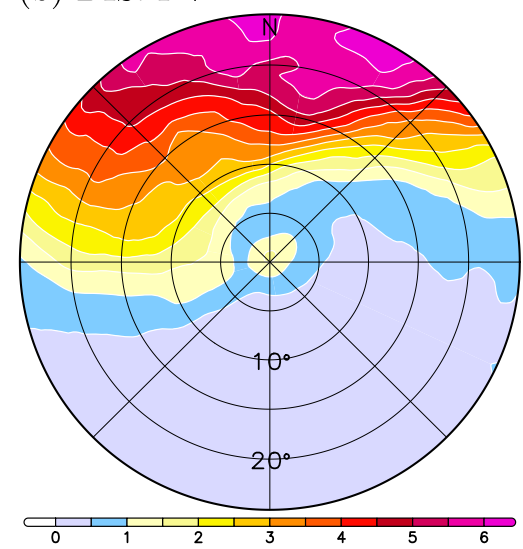

(e) DIS: Mean PV

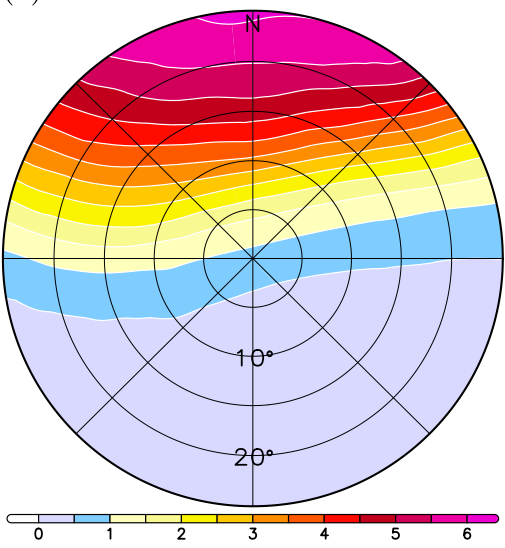

(h) DIS: Eddy PV

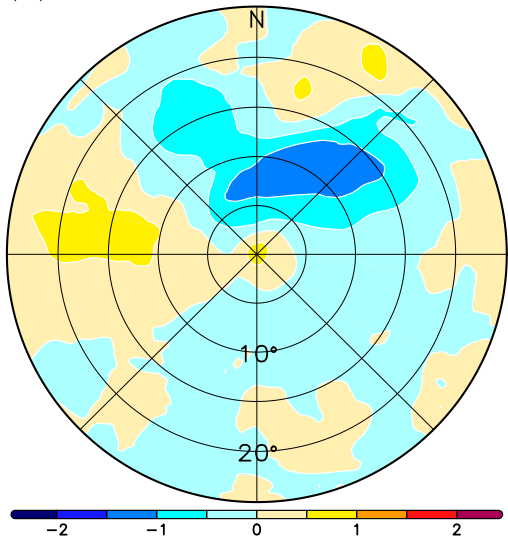

(c) I-D: PV

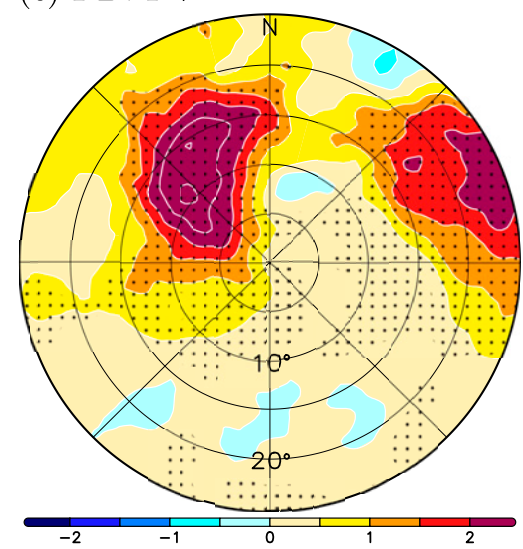

(f) I-D: Mean PV

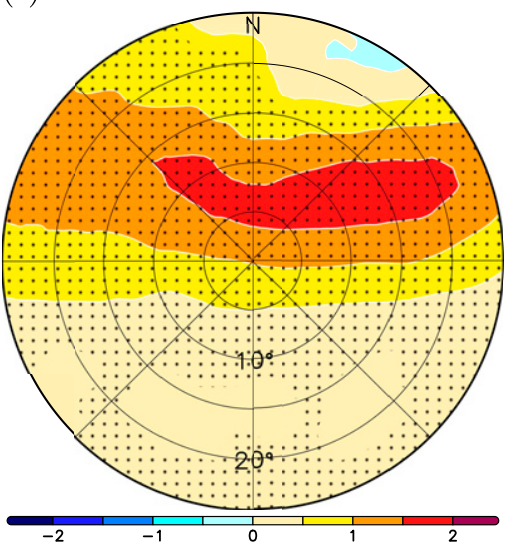

(i) I-D: Eddy PV

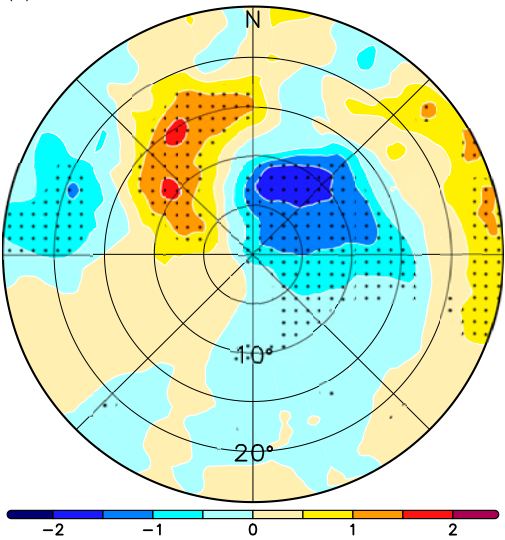

FIG. 7. Composite PV at the $330 \mathrm{~K}$ isentropic surface (PVU) relative to the ETTC centers at $T_{0}$ for (left) INT, (center) DIS, and (right) their difference (INT minus DIS). (a)-(c) The total field. (d)-(f) The mean field. (g)-(i) The eddy field. Details are as in Fig. 6.

\section{b. Upper levels}

Because PV in the upper levels can be a good indicator of ETTC development as shown in section 3, composite fields of $\mathrm{PV}$ at the $330 \mathrm{~K}$ isentropic surface are shown in Figs. 7a-c. In both the INT and DIS cases, high PV values are observed northwest of the ETTC center (Figs. 7a,b), which is a typical structure of a baroclinic disturbance. The difference between the INT and DIS cases within the radius of $15^{\circ}$ is large and statistically significant to the northwest of the ETTC center (Fig. 7c), whereas it is smaller to the northeast.

To explore the relationship between planetary-scale environments and synoptic-scale transient disturbances, we separated the total PV fields into the mean fields (Figs. 7d-f) and the eddy fields (Figs. 7g-i) on the basis of the 30-day Lanczos 
filter. In the eddy fields, it is noteworthy that a large area of negative PV northeast of the ETTCs was dominant over a positive PV northwest of the ETTCs in both the INT and DIS cases (Figs. 7g,h). In marked contrast to the total field, the difference between the INT and DIS cases also displays a large anomaly of negative PV northeast of the ETTCs (Fig. 7i); furthermore, a positive PV anomaly northwest of the ETTCs in the eddy field is weaker than that in the total field. This contrast between the total and eddy fields results from a positive PV anomaly in the mean field (Fig. 7f). Northeast of the ETTC center, the PV anomaly in the total field is small, because the positive $\mathrm{PV}$ anomaly in the mean field counteracts the negative PV anomaly in the eddy field. Northwest of the ETTC center, on the other hand, the positive PV anomaly in the total field is large, because the positive PV anomaly in the mean field enhances that in the eddy field. The high PV in the mean field in the INT cases is attributed to their relatively high latitudes as shown in Fig. 4e.

The time evolution of the upper-level PV is shown in lag composite analysis for $T_{0}-24 \mathrm{~h}$ and $T_{0}-12 \mathrm{~h}$ (Fig. 8). In the INT cases, the total field shows that the area of high PV northwest of the ETTCs expands and strengthens from $T_{0}-$ $24 \mathrm{~h}$ to $T_{0}$ (Figs. $7 \mathrm{a}, 8 \mathrm{a}, \mathrm{c}$ ). The eddy field shows that a positive PV moves from the northwest toward the ETTC center during the $24 \mathrm{~h}$ before $T_{0}$ (Figs. $7 \mathrm{~g}, 8 \mathrm{e}, \mathrm{g}$ ); because this motion of the PV pattern is relative to the northeastward motion of the ETTCs on average (Fig. 3), the positive PV moved eastward relative to Earth's surface. This is consistent with the interaction between ETTCs and eastward-moving upper-level troughs (Hart et al. 2006). The eddy field northeast of the ETTCs shows that the area of negative PV northeast of the ETTCs is almost stationary and was amplified near the ETTC center. This characteristic agrees well with previous studies showing ridge amplification downstream (east) of ETTCs due to the outflow associated with diabatic heating of the ETTCs (Grams and Archambault 2016; Keller et al. 2019). These characteristics of the time evolution are more intense in the INT cases than in the DIS cases (Figs. 8b,d,f,h).

In summary, the total PV field in the upper levels consists of three different components: positive eddy PV accompanied by eastward-moving troughs northwest of the ETTCs, negative eddy PV due to ridge building to the northeast, and positive mean PV in the planetary-scale environment. To quantify the difference in the PV fields between the three classes, we defined three indices: the PVnw index is the average of the total PV in an area northwest of the center (the black outline in Fig. 8d), and PVEnw and PVEne indices are the averages of the eddy PV in areas northwest and northeast of the center, respectively (the black outlines in Fig. 8h). Figures 9a-c and Table 1 demonstrate that ETTC development is in good agreement with the magnitudes of the positive PVnw, positive PVEnw, and negative PVEne at both $T_{0}-12$ and $T_{0}$. It should be also noted that the PV fields at $350 \mathrm{~K}$ show characteristics similar to those at $330 \mathrm{~K}$ (Fig. S2 in the supplemental material), except that the negative eddy PV to the northeast is more dominant over the positive eddy PV to the northwest at $350 \mathrm{~K}$ than at $330 \mathrm{~K}$.

\section{c. The Klein et al. (2002) parameters}

As described in section 1, Klein et al. (2002) proposed three synoptic-scale parameters (K02 parameters hereafter) that diagnose the development of ETTCs: divergence at $200 \mathrm{hPa}$, horizontal advection of positive vorticity at $500 \mathrm{hPa}$, and temperature advection at $925 \mathrm{hPa}$. They showed that the combination of these parameters could explain the development of ETTCs for three cases in the western North Pacific. Ritchie and Elsberry (2003, 2007) conducted idealized experiments in which ETTCs are affected by upper-level troughs with different strengths and locations, and confirmed that the three K02 parameters can discriminate reintensifying ETTCs robustly. Therefore, it is interesting to examine statistically whether the K02 parameters are applicable to ETTC cases in the real atmosphere. It may also be practically useful to determine in which segment the K02 parameters differ significantly between reintensifying and dissipating ETTCs.

The composite fields of the three K02 parameters are shown in Fig. 10 for $T_{0}-12 \mathrm{~h}$. Because the INT cases have not started to develop at this time (Fig. 1), the parameters appear to be little affected by the intensity of the ETTCs themselves. The fact that three parameters for the INT cases are largest within the radius of $5^{\circ}$ of the ETTC center (Figs. 10a,c,e) merely reflects the structures of the ETTCs. However, significant differences between the INT and DIS cases are evident away from the ETTC center: anomalies in upper-level divergence and positive vorticity advection to the north at $10^{\circ}-20^{\circ}$ radius (Figs. 10b,d), and a positive temperature advection anomaly to the northeast at $5^{\circ}-15^{\circ}$ radius (Fig. 10f). The anomaly in the positive vorticity advection north of the ETTCs is consistent with the zonal gradient of the PV anomaly between the positive anomaly northwest and the negative anomaly northeast (Fig. 8h) in the environmental westerly flow.

The three K02 parameters occur in a similar location, because all of them have a theoretical connection with updrafts. Upper-level divergence is directly linked to an updraft by the continuity equation. Positive vorticity advection and warm-air advection are also linked to an updraft by the traditional form of the quasigeostrophic omega equation; also note that Kitabatake et al. (2007) showed an overlap between positive vorticity advection and warm-air advection northeast of Typhoon Songda (2004) during its interaction with an upperlevel trough. An upward anomaly of the vertical motion at $500 \mathrm{hPa}$ (Fig. 10h) and at $700 \mathrm{hPa}$ (not shown) indeed appears near the anomalies of the three K02 parameters. To quantify the difference in the updraft between the three ETTC classes, we defined the Wne index as the average vertical velocity in a segment northeast of the ETTC center (the black outline in Fig. 10h). Figure 9d and Table 1 show that ETTC development agrees well with small Wne values (strong updraft) at $T_{0}-12 \mathrm{~h}$ and $T_{0}$.

\section{Discussion}

\section{a. Relationship between large-scale factors}

Having demonstrated that several large-scale (planetary- or synoptic-scale) factors are in good agreement with ETTC development, we then need to establish whether the factors affect the ETTCs independently or are merely different aspects of the same process. The correlation between the indices (Figs. 5, 9, 
(a) INT: PV (-24 h)

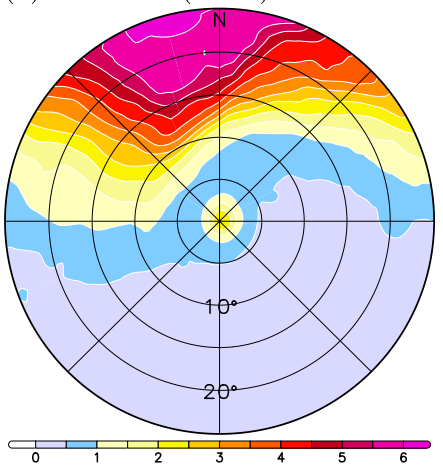

(c) INT: PV $(-12 \mathrm{~h})$

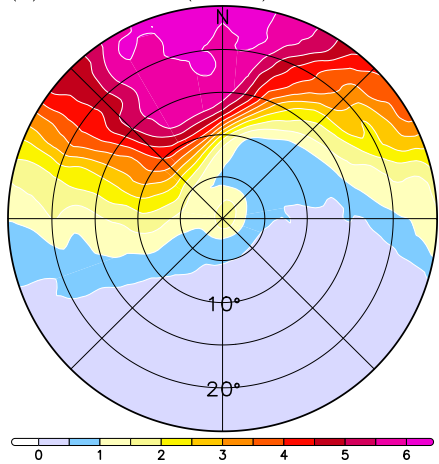

(e) INT: Eddy PV (-24 h)

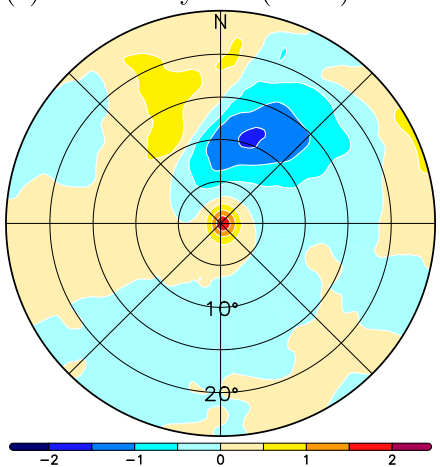

(g) INT: Eddy PV (-12 h)

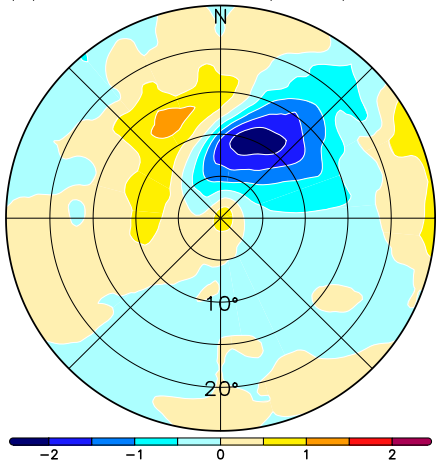

(b) I-D: PV (-24 h)

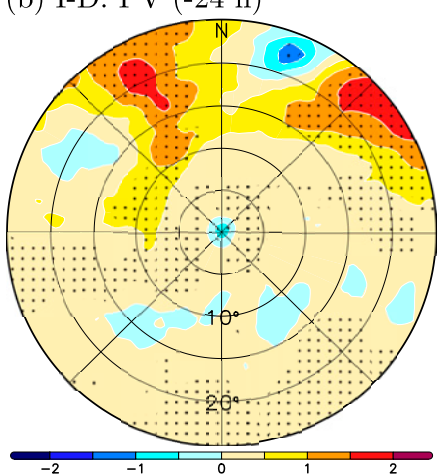

(d) I-D: PV (-12 h)

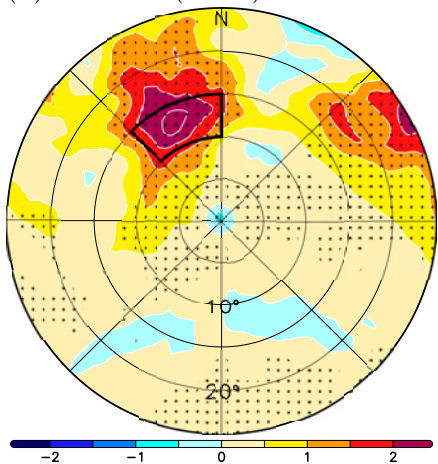

(f) I-D: Eddy PV (-24 h)

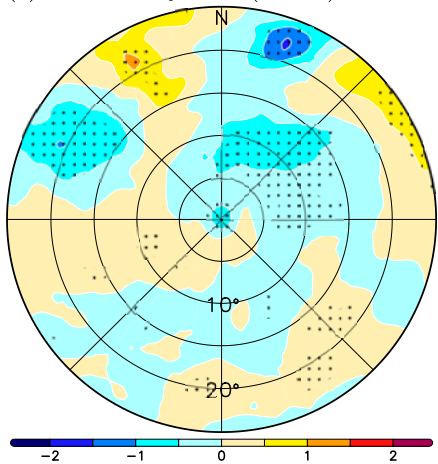

(h) I-D: Eddy PV (-12 h)

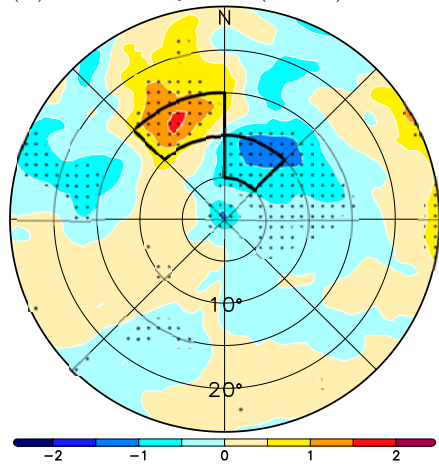

FIG. 8. Composite PV fields at the $330 \mathrm{~K}$ isentropic surface (PVU) relative to the ETTC centers for (left) the INT cases and (right) the difference between the INT and DIS cases. (a),(b) The total field at $T_{0}-24 \mathrm{~h}$. (c),(d) The total field at $T_{0}-12 \mathrm{~h}$. (e),(f) The eddy field at $T_{0}-24 \mathrm{~h}$. (g),(h) The eddy field at $T_{0}-12 \mathrm{~h}$. The black outline in (d) indicates the area for determining the PVnw index, and those in (h) indicate the areas for determining the PVEnw and PVEne indices. Other details are as in Fig. 6. 
(a) PVnw

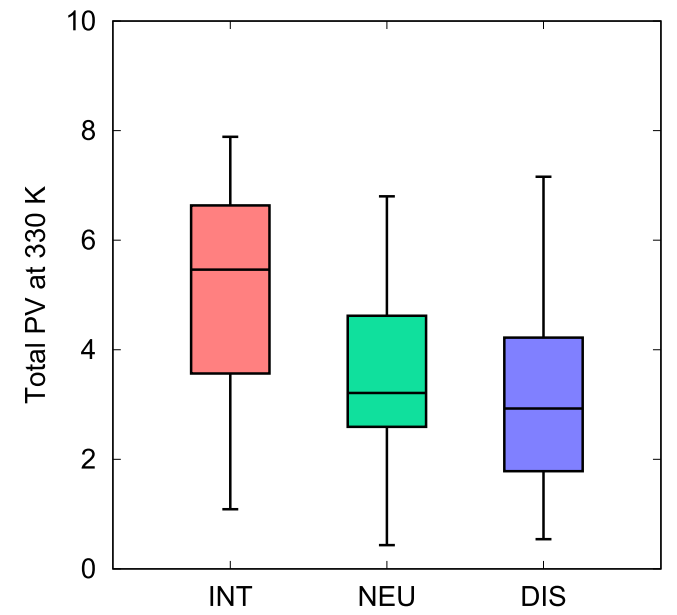

(c) PVEne

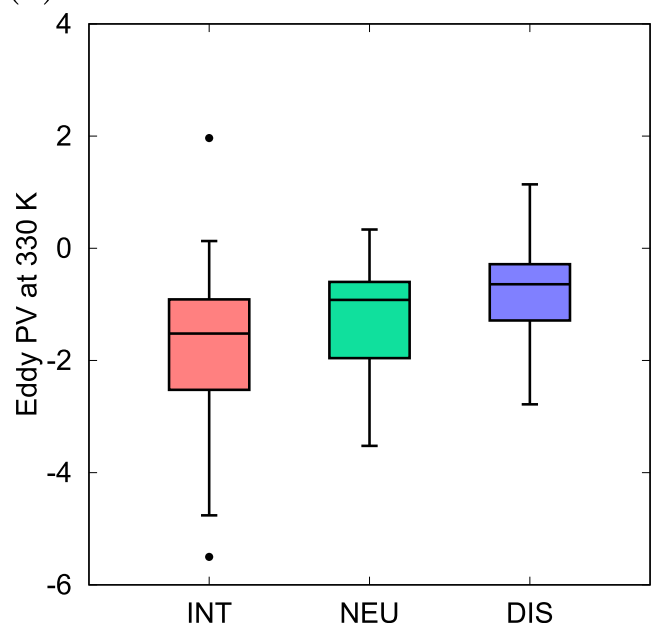

(b) PVEnw

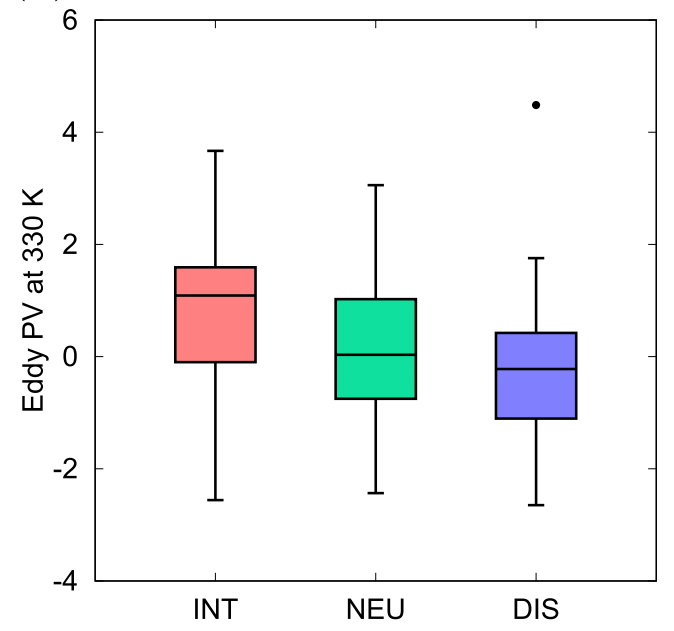

(d) Wne

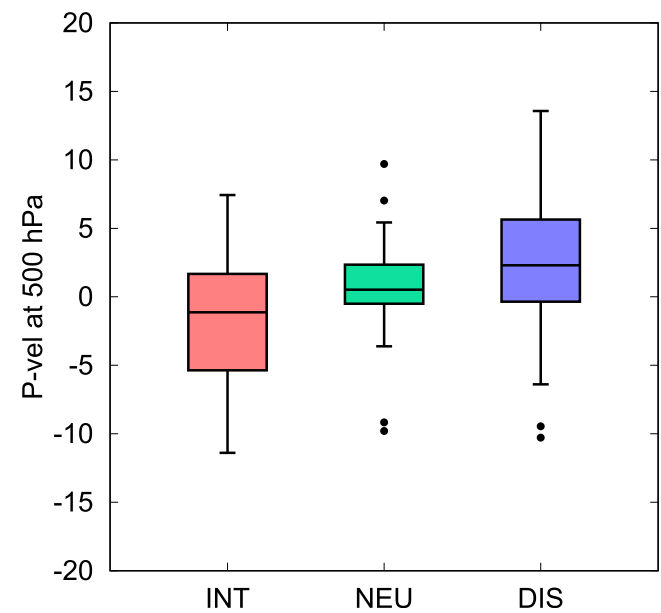

FIG. 9. Box-and-whisker plots of indices at $T_{0}-12 \mathrm{~h}$ for the INT (red), NEU (green), and DIS (blue) cases. (a) PVnw (PVU). (b) PVEnw (PVU). (c) PVEne (PVU). (d) Wne $\left(\mathrm{hPa} \mathrm{h}^{-1}\right)$. The variables are averaged over the areas indicated in Figs. 8d, 8h, and 10h. Other details are as in Fig. 5.

Table 1) may provide some clues. For example, Fig. 11a is a scatterplot showing the relationship between the northwestern eddy PV index (PVEnw) and the northeastern vertical velocity index (Wne) at $T_{0}-12 \mathrm{~h}$ (see also Figs. 9b,d). The individual ETTCs in each class (the circles) have some variability, whereas the means of each class (the triangles) indicate the difference between the classes. Here, we focus on the sign of the linear regression for each class. The regression coefficients for all three ETTC classes are negative (the regression line slope from upper left to lower right; Fig. 11a), indicating that positive eddy PV anomalies northwest of the ETTCs are related to the updraft northeast of the ETTCs. This result is consistent with the traditional form of the quasigeostrophic omega equation in that the ascending motion occurs east of eastward-moving upper-level troughs with the positive PV anomaly (Kitabatake et al. 2007).

As Figs. 5e and 9 and Table 1 demonstrate that ETTC development is linked to $\mathrm{PV}$ at the $330 \mathrm{~K}$ isentropic level in both the mean and eddy fields, it is interesting to examine this relationship more closely. Figure $11 \mathrm{~b}$ shows a scatterplot diagram for the mean $\mathrm{PV}$ averaged over a $10^{\circ}$ radius from the ETTC centers (referred to as PVM) and the northwest eddy PV index (PVEnw) at $T_{0}$. The regression lines for the three classes have inconsistent signs, which implies that the phase and magnitude of the eastward-moving troughs have little dependence on the environmental PV. The plot of the relationship between the mean PV and the northeast eddy PV index (PVEne) at $T_{0}$ (Fig. 11c), shows significant negative regression coefficients for all three classes. Furthermore, the magnitudes of PVEne and PVM are nearly the same for the individual ETTCs. This indicates that eddy PV northeast of the ETTCs almost cancels mean PV, resulting in the low total PV to the northeast (Fig. 7). In general, total PV hardly becomes negative in the Northern Hemisphere, because such a condition satisfies either static, inertial, or symmetric instability (Schultz and Schumacher 1999). Therefore, the mean PV may limit the magnitude of the 
(a) INT: Div. at $200 \mathrm{hPa}$

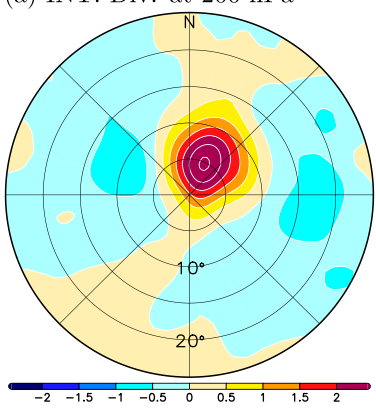

(c) INT: Vor. Adv. at $500 \mathrm{hPa}$

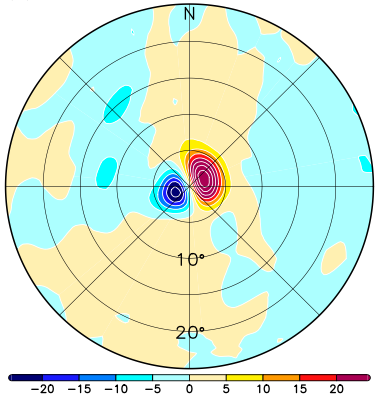

(e) INT: Tem. Adv. at $925 \mathrm{hPa}$

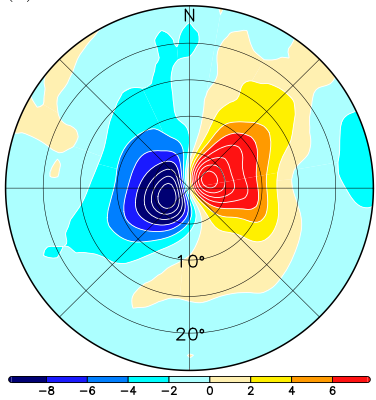

(g) INT: P-vel at $500 \mathrm{hPa}$

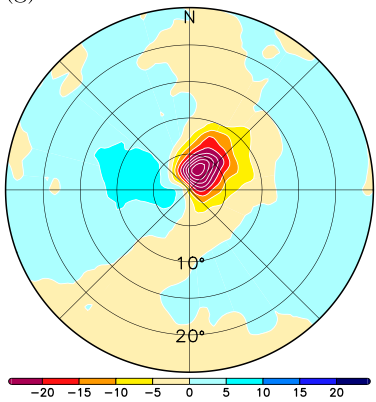

(b) I-D: Div. at $200 \mathrm{hPa}$

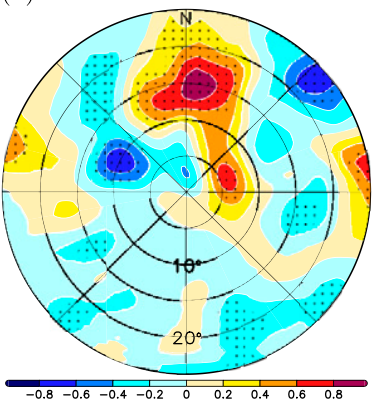

(d) I-D: Vor. Adv. at $500 \mathrm{hPa}$

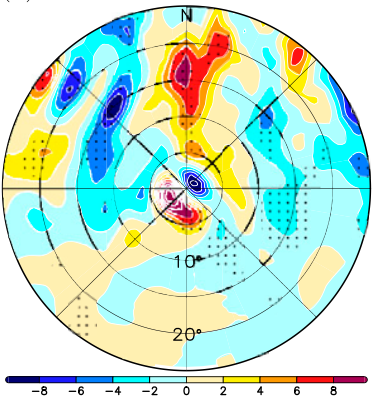

(f) I-D: Tem. Adv. at $925 \mathrm{hPa}$

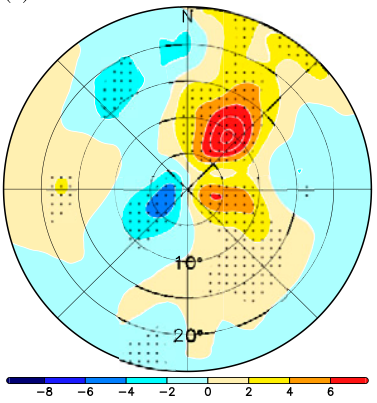

(h) I-D: P-vel at $500 \mathrm{hPa}$

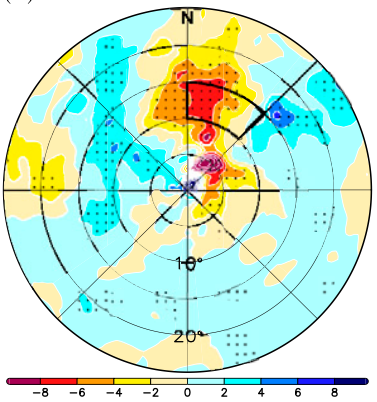

FIG. 10. Composite fields relative to the ETTC centers at $T_{0}-$ $12 \mathrm{~h}$ for (left) the INT cases, and (right) the difference between the INT and DIS cases. (a),(b) Divergence at $200 \mathrm{hPa}\left(10^{-5} \mathrm{~s}^{-1}\right)$. (c),(d) Horizontal advection of relative vorticity at $500 \mathrm{hPa}\left(10^{-10} \mathrm{~s}^{-2}\right)$. (e),(f) Horizontal advection of temperature at $925 \mathrm{hPa}\left(10^{-5} \mathrm{~K} \mathrm{~s}^{-1}\right)$. (g),(h) Pressure vertical velocity at $500 \mathrm{hPa}\left(\mathrm{hPah}^{-1}\right)$. The black outline in (h) indicates the area for determining the Wne index. Other details are as in Fig. 6.

negative eddy PV, which may be one reason why ETTCs tend to develop in environments with high upper-level PV at relatively high latitudes (Figs. 4e, 5e). Grams and Archambault (2016) also demonstrated that intense ridge building in the

upper levels is in association with high mean PV at high latitudes (see their Table 2 and Fig. S15).

Some studies discussed the mechanisms in which a downstream ridge in the upper levels intensifies a cyclone in the lower levels. Griffin and Bosart (2014) proposed that an amplification of an upper-level ridge (i.e., negative eddy PV) to the east of TC Edisoana (1990) in tandem with an upper-level trough to the west was responsible for its reintensification after ET through baroclinically forced ascent. Riboldi et al. (2019) compared upper-level troughs accelerating eastward propagation and those decelerating eastward propagation during the interaction with recurving TCs, and demonstrated that intense ridge building observed in the latter group was associated with strong ascending motion favorable for baroclinic development. As our statistical analysis only indicates the relationship between ETTC development and large-scale conditions, this mechanism should be examined more systematically and quantitatively using idealized numerical experiments (Ritchie and Elsberry 2001, 2003, 2007; Riemer et al. 2008).

\section{b. Comparison with previous studies}

Some of the large-scale factors examined in this study can be compared with those in previous studies. Deep upper-level troughs or high PV northwest of reintensifying ETTCs have been investigated by many previous studies (Klein et al. 2002; Agustí-Panareda et al. 2004; Evans and Prater-Mayes 2004; Hart et al. 2006; Grams et al. 2013) as well as by this study (Figs. 7, 8). The upper-level troughs appear to be related to the K02 parameters (Klein et al. 2002; Ritchie and Elsberry 2003, 2007). This study statistically confirmed that the three K02 parameters about $1000 \mathrm{~km}$ north or northeast of the ETTC centers at $T_{0}-12 \mathrm{~h}$ are significantly larger for the INT cases than the DIS cases. In addition, Hart et al. (2006) found that troughs at $500 \mathrm{hPa}$ for reintensifying ETTCs tilt in the northwest-southeast direction, whereas those for the dissipating ETTCs tilt in the northeast-southwest direction, which result in the difference in PV flux into the ETTCs (see their Figs. 8 and 12). The difference in trough patterns at $500 \mathrm{hPa}$ is also observed in Figs. 6a-c.

Harr et al. (2000) used an empirical orthogonal function analysis to objectively classify two circulation patterns, called the northwest and northeast patterns, associated with 30 ETTCs over the western North Pacific (see their Fig. 1). They noted that the average central pressures in ETTCs associated with the northwest pattern was $13 \mathrm{hPa}$ deeper than that associated with the northeast pattern. Our composite fields of lowand midlevel geopotential height for the INT and DIS cases are similar to their northwest and northeast patterns, respectively (Figs. 6a-f). Therefore, the relationship we found between ETTC development and large-scale circulation in this study is consistent with the findings of Harr et al. (2000), although the classification methods in the two studies are totally different.

In general, environmental fields shift poleward in warm seasons and equatorward in cold seasons (Fig. 4). Even taking into account this seasonal shift in latitude, the INT cases occur in environments at higher latitudes than the DIS cases (Fig. 5). In particular, ETTC development is in good agreement with high upper-level PV and its horizontal gradient. Our composite 
(a) Wne - PVEnw $(-12 \mathrm{~h})$

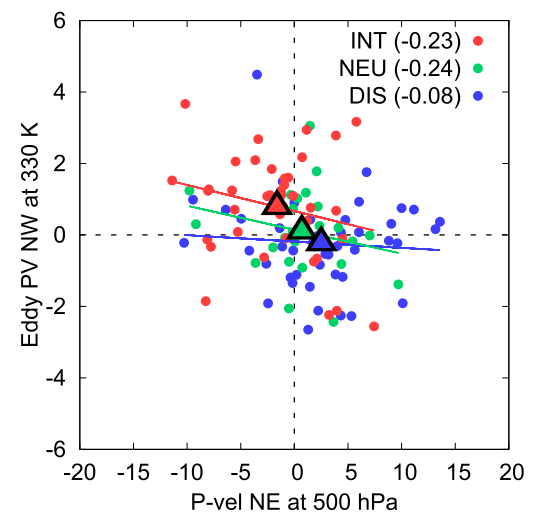

(b) PVM - PVEnw (0 h)

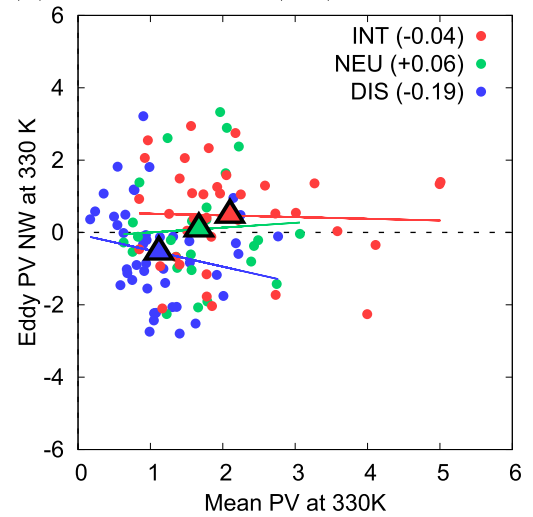

(c) PVM - PVEne $(0 \mathrm{~h})$

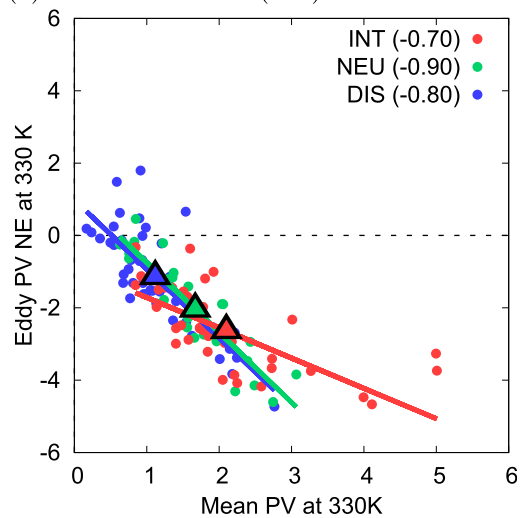

FIG. 11. Scatterplot comparing indices associated with ETTCs. (a) Wne and PVEnw at $T_{0}-12 \mathrm{~h}$. (b) PVM and PVEnw at $T_{0}$. (c) PVM and PVEne at $T_{0}$. The circles are individual ETTCs for the INT (red), NEU (green), and DIS (blue) cases. The triangles are the mean of each ETTC class. Solid lines are the linear regression for each class; thick lines denote the significance level of 0.05 . The numbers in the parentheses are correlation coefficients.

analysis demonstrated that high upper-level PV in the mean field for the INT cases is important for increasing the total PV northwest of the ETTCs (Fig. 7) and for determining the magnitude of the negative eddy PV northeast of the ETTCs (Fig. 11c). The steep gradient of upper-level PV may favor the development of baroclinic waves (Hoskins and Hodges 2019). On the other hand, the difference in favorable latitudes explains the location of the INT and DIS cases relative to the axis of the westerly jet stream (Fig. 4d); the former near the axis and the latter south of the axis, which results in the difference in vorticity at $500 \mathrm{hPa}$ (Fig. 5d). This finding is consistent with the finding of Agustí-Panareda et al. (2005) in that ETTC development prefers cyclonic shear over anticyclonic shear. Wernli et al. (1998) showed that the structure of a cyclone is oriented northwest-southeast in a cyclonic shear environment, and northeast-southwest in an anticyclonic shear environment. This may be another reason for the relationship between ETTC development and the orientation of upper-level troughs observed by Hart et al. (2006) and in this study.

It is interesting to note that the environments supporting diabatic development (SST and maximum potential intensity) and baroclinic development (Eady growth rate and EPT gradient) do not necessarily show good performance in our analysis (Fig. 5 and Table 1), although they are considered to be favorable environments for TCs, extratropical cyclones, or ET (Hoskins and Valdes 1990; Hart and Evans 2001; Camargo et al. 2007; Yanase et al. 2014). In contrast to our results, Hart et al. (2006) found that reintensifying ETTCs occurred over warmer ocean than dissipating ETTCs in the North Atlantic Ocean. Therefore, we have to consider the roles of these environmental factors carefully. Their influences may be obscured by more dominant effect of the upper-level PV; the low $\mathrm{PV}$ in relatively low latitudes may counteract the influence of high SST and the Eady growth rate exceeding 0.3 day $^{-1}$, causing many DIS cases particularly in May and OctoberNovember (Fig. 4). The vertical shear associated with the Eady growth rate may play complicated roles due to its two-sided effects on cyclone dynamics (Yanase and Niino 2019); whereas it is a favorable condition for extratropical cyclones, it may be detrimental to TCs until they complete ET processes. These issues may be addressed more properly in future by analyzing an enormous number of ETTCs, or by controlling the environmental fields in idealized experiments.

\section{c. Validity of the methodology}

This study relies on the best track dataset, which is based on available observation and atmospheric analysis data. Although determining the status of the ET process is not always easy, the JMA operational analysis agrees well with other independent approaches; for instance, Bieli et al. (2019) confirmed that their objective classification of ET, based on the cyclone phase space approach (Hart 2003), agrees best with the JMA best track record in the western North Pacific.

We analyzed only ETTCs that displayed large intensity change to compose our INT and DIS classes so as to ensure results that are as robust as possible. We also confirmed that our main conclusion does not change, if the thresholds of $\Delta p_{c}$ for the INT and DIS classes are reduced from 6 to $4 \mathrm{hPa}$ (referred to as INTp4 and DISp4 classes, respectively); the seasonality, locations, and the upper-level PV fields for the INTp4 an DISp4 are similar to those for the INT and DIS cases (Figs. S3-S5 in the supplemental material), except that the INTp4 cases are more frequent in September than in October.

One may be concerned that a few DIS cases at low latitudes (Fig. 4) could affect our conclusion. Therefore, we repeated the composite analysis after removing ETTCs that occurred at latitudes lower than $30^{\circ} \mathrm{N}$. This resulted in PV patterns similar to those in Fig. 7, although the difference in mean PV between the INT and DIS cases was slightly smaller (not shown). We conclude that ETTCs at low latitudes did not contaminate the results significantly. We note that the two DIS cases at very low latitudes $\left(18.0^{\circ}\right.$ and $\left.18.7^{\circ} \mathrm{N}\right)$ were nevertheless in a baroclinic environment associated with cold fronts that extended from the centers of extratropical cyclones northeast of the ETTCs.

We hope that better understanding of the large-scale conditions associated with ET will also help improve the ET analysis method. 


\section{Summary}

We analyzed ETTC development using the 40-yr JMA best track dataset and the JRA-55. The most active season for intensifying ETTCs was early autumn, whereas that for dissipating ETTCs was late autumn. Intensifying ETTCs tended to occur at higher latitudes than dissipating ETTCs, even when the seasonal latitude shift of environmental fields was taken into account. In association with this difference in latitudes, intensifying ETTCs, on average, occur in environments with high upper-level PV and steeper PV gradients than dissipating ETTCs.

Our composite analysis statistically confirmed the significant characteristics of several large-scale conditions for ETTC development: low-level circulation patterns, the presence of upper-level eastward-moving troughs northwest of the ETTCs and their differing orientations, and upper-level ridge building northeast of the ETTCs. These are consistent with previous studies. Furthermore, the separation of the large-scale PV field into mean and eddy fields clarified the different roles of planetary-scale environments and synoptic-scale dynamics. The positive PV anomaly northwest of the ETTCs combines a positive mean PV and positive eddy PV, whereas the small PV anomaly northeast of the ETTCs results from a negative eddy PV that offsets the positive mean PV. The positive and negative eddy PV patterns appear to be associated with the approach of eastward-moving troughs and the ridge building caused by the ETTCs themselves, respectively, a result that agrees well with previous studies. Our main finding is that the ridge building is stronger in the intensifying ETTCs which is associated with high mean PV at higher latitudes.

Although this statistical study supports some relationships between ETTC development and large-scale conditions, we should clarify how these large-scale conditions affect the dynamics of ETTC development in more detail, and what is the difference in the dynamics between ETTCs and ordinary extratropical cyclones in future study.

Acknowledgments. We acknowledge helpful comments by Drs. Naoko Kitabatake, Christian Grams, Julian Quinting, Jacopo Riboldi, Hiroshi Niino, Ryuichi Kawamura, Shuhei Maeda, and Akiyoshi Wada, as well as three anonymous reviewers. Maximum potential intensity was calculated using the FORTRAN program from the website of Dr. Kerry A. Emanuel. This research was supported by JSPS KAKENHI Grants 19H05696, 19H00705, and 19H01973.

Data availability statement. The data that support the finding of this study were derived from the two source datasets: the JMA best track data (Japan Meteorological Agency 2019b) and the JRA-55 (Japan Meteorological Agency 2019a). The derived data are available from https:/climate.mri-jma.go.jp/ pub/archives/Yanase-et-al_TCET/.

\section{REFERENCES}

Agustí-Panareda, A., C. Thorncroft, G. Craig, and S. Gray, 2004: The extratropical transition of Hurricane Irene (1999): A potential-vorticity perspective. Quart. J. Roy. Meteor. Soc., 130, 1047-1074, https://doi.org/10.1256/qj.02.140.
—, S. L. Gray, G. C. Craig, and C. Thorncroft, 2005: The extratropical transition of Tropical Cyclone Lili (1996) and its crucial contribution to a moderate extratropical development. Mon. Wea. Rev., 133, 1562-1573, https://doi.org/10.1175/MWR2935.1.

Archambault, H. M., L. F. Bosart, D. Keyser, and J. M. Cordeira, 2013: A climatological analysis of the extratropical flow response to recurving western North Pacific tropical cyclones. Mon. Wea. Rev., 141, 2325-2346, https://doi.org/10.1175/MWRD-12-00257.1.

— D. Keyser, L. F. Bosart, C. A. Davis, and J. M. Cordeira, 2015: A composite perspective of the extratropical flow response to recurving western North Pacific tropical cyclones. Mon. Wea. Rev., 143, 1122-1141, https://doi.org/10.1175/MWR-D-14-00270.1.

Bieli, M., S. J. Camargo, A. H. Sobel, J. L. Evans, and T. Hall, 2019: A global climatology of extratropical transition. Part II: Statistical performance of the cyclone phase space. J. Climate, 32, 3583-3597, https://doi.org/10.1175/JCLI-D-18-0052.1.

Bister, M., and K. A. Emanuel, 2002: Low frequency variability of tropical cyclone potential intensity. 1. Interannual to interdecadal variability. J. Geophys. Res., 107, 4801, https://doi.org/ 10.1029/2001JD000776.

Camargo, S. J., K. A. Emanuel, and A. H. Sobel, 2007: Use of a genesis potential index to diagnose ENSO effects on tropical cyclone genesis. J. Climate, 20, 4819-4834, https://doi.org/ 10.1175/JCLI4282.1.

Evans, C., and Coauthors, 2017: The extratropical transition of tropical cyclones. Part I: Cyclone evolution and direct impacts. Mon. Wea. Rev., 145, 4317-4344, https://doi.org/10.1175/ MWR-D-17-0027.1.

Evans, J. L., and B. E. Prater-Mayes, 2004: Factors affecting the posttransition intensification of Hurricane Irene (1999). Mon. Wea. Rev., 132, 1355-1368, https://doi.org/10.1175/1520-0493(2004)132<1355: FATPIO $>2.0 . C O ; 2$.

Grams, C. M., and H. M. Archambault, 2016: The key role of diabatic outflow in amplifying the midlatitude flow: A representative case study of weather systems surrounding western North Pacific extratropical transition. Mon. Wea. Rev., 144, 3847-3869, https://doi.org/10.1175/MWR-D-15-0419.1.

- S. C. Jones, C. A. Davis, P. A. Harr, and M. Weissmann, 2013: The impact of Typhoon Jangmi (2008) on the midlatitude flow. Part I: Upper-level ridgebuilding and modification of the jet. Quart. J. Roy. Meteor. Soc., 139, 2148-2164, https://doi.org/10.1002/qj.2091.

Griffin, K. S., and L. F. Bosart, 2014: The extratropical transition of Tropical Cyclone Edisoana (1990). Mon. Wea. Rev., 142, 2772-2793, https://doi.org/10.1175/MWR-D-13-00282.1.

Harr, P. A., R. L. Elsberry, and T. F. Hogan, 2000: Extratropical transition of tropical cyclones over the western North Pacific. Part II: The impact of midlatitude circulation characteristics. Mon. Wea. Rev., 128, 2634-2653, https://doi.org/10.1175/15200493(2000)128<2634:ETOTCO > 2.0.CO;2.

Hart, R. E., 2003: A cyclone phase space derived from thermal wind and thermal asymmetry. Mon. Wea. Rev., 131, 585-616, https:// doi.org/10.1175/1520-0493(2003)131<0585:ACPSDF>2.0.CO;2.

_, and J. L. Evans, 2001: A climatology of the extratropical transition of Atlantic tropical cyclones. J. Climate, 14, 546-564, https:// doi.org/10.1175/1520-0442(2001)014<0546:ACOTET>2.0.CO;2.

,-- , and C. Evans, 2006: Synoptic composites of the extratropical transition life cycle of North Atlantic tropical cyclones: Factors determining posttransition evolution. Mon. Wea. Rev., 134, 553-578, https://doi.org/10.1175/MWR3082.1.

Hoskins, B. J., and P. J. Valdes, 1990: On the existence of stormtracks. J. Atmos. Sci., 47, 1854-1864, https://doi.org/10.1175/ 1520-0469(1990)047<1854:OTEOST>2.0.CO;2. 
, and K. I. Hodges, 2019: The annual cycle of Northern Hemisphere storm tracks. Part I: Seasons. J. Climate, 32, 17431760, https://doi.org/10.1175/JCLI-D-17-0870.1.

Ishii, M., A. Shouji, S. Sugimoto, and T. Matsumoto, 2005: Objective analyses of sea-surface temperature and marine meteorological variables for the 20th century using ICOADS and the Kobe collection. Int. J. Climatol., 25, 865-879, https:// doi.org/10.1002/joc.1169.

Japan Meteorological Agency, 2019a: JRA-55-The Japanese 55-year Reanalysis. Accessed 10 February 2019, https://jra.kishou.go.jp/ JRA-55/index_en.html.

— 2019b: RSMC best track data. Accessed 11 January 2019, https://www.jma.go.jp/jma/jma-eng/jma-center/rsmc-hp-pubeg/besttrack.html.

Jones, S. C., and Coauthors, 2003: The extratropical transition of tropical cyclones: Forecast challenges, current understanding, and future directions. Wea. Forecasting, 18, 1052-1092, https:// doi.org/10.1175/1520-0434(2003)018<1052:TETOTC $>2.0$. $\mathrm{CO} ; 2$.

Keller, J. H., and Coauthors, 2019: The extratropical transition of tropical cyclones. Part II: Interaction with the midlatitude flow, downstream impacts, and implications for predictability. Mon. Wea. Rev., 147, 1077-1106, https://doi.org/10.1175/MWR-D-170329.1.

Kitabatake, N., 2011: Climatology of extratropical transition of tropical cyclones in the western North Pacific defined by using cyclone phase space. J. Meteor. Soc. Japan, 89, 309-325, https://doi.org/10.2151/jmsj.2011-402.

— S. Hoshino, K. Bessho, and F. Fujibe, 2007: Structure and intensity change of Typhoon Songda (0418) undergoing extratropical transition. Pap. Meteor. Geophys., 58, 135-153, https://doi.org/10.2467/mripapers.58.135.

Klein, P. M., P. A. Harr, and R. L. Elsberry, 2002: Extratropical transition of western North Pacific tropical cyclones: Midlatitude and tropical cyclone contributions to reintensification. Mon. Wea. Rev., 130, 2240-2259, https://doi.org/10.1175/1520-0493(2002)130<2240: ETOWNP $>2.0 . \mathrm{CO} ; 2$

Kobayashi, S., and Coauthors, 2015: The JRA-55 reanalysis: General specifications and basic characteristics. J. Meteor. Soc. Japan, 93, 5-48, https://doi.org/10.2151/jmsj.2015-001.

Li, K., and H.-M. Xu, 2015: Comparative analysis of the intensifying and weakening landfall tropical cyclones during extratropical transition over China. J. Trop. Meteor., 21, 23-33, https://doi.org/1006-8775(2015)-01-0023-11.

Lindzen, R. S., and B. Farrell, 1980: A simple approximate result for the maximum growth rate of baroclinic instabilities. J. Atmos. Sci., 37, 1648-1654, https://doi.org/10.1175/15200469(1980)037<1648:ASARFT>2.0.CO;2.

McTaggart-Cowan, R., J. R. Gyakum, and M. K. Yau, 2001: Sensitivity testing of extratropical transitions using potential vorticity inversions to modify initial conditions: Hurricane
Earl case study. Mon. Wea. Rev., 129, 1617-1636, https:// doi.org/10.1175/1520-0493(2001)129<1617:STOETU>2.0. $\mathrm{CO} ; 2$.

Quinting, J. F., and S. C. Jones, 2016: On the impact of tropical cyclones on Rossby wave packets: A climatological perspective. Mon. Wea. Rev., 144, 2021-2048, https://doi.org/10.1175/ MWR-D-14-00298.1.

Riboldi, J., M. Röthlisberger, and C. M. Grams, 2018: Rossby wave initiation by recurving tropical cyclones in the western North Pacific. Mon. Wea. Rev., 146, 1283-1301, https://doi.org/ 10.1175/MWR-D-17-0219.1.

— C. M. Grams, M. Riemer, and H. M. Archambault, 2019: A phase locking perspective on Rossby wave amplification and atmospheric blocking downstream of recurving western North Pacific tropical cyclones. Mon. Wea. Rev., 147, 567-589, https://doi.org/10.1175/MWR-D-18-0271.1.

Riemer, M., S. C. Jones, and C. A. Davis, 2008: The impact of extratropical transition on the downstream flow: An idealized modelling study with a straight jet. Quart. J. Roy. Meteor. Soc., 134, 69-91, https://doi.org/10.1002/qj.189.

Ritchie, E. A., and R. L. Elsberry, 2001: Simulations of the transformation stage of the extratropical transition of tropical cyclones. Mon. Wea. Rev., 129, 1462-1480, https://doi.org/10.1175/ 1520-0493(2001)129<1462:SOTTSO > 2.0.CO;2.

$\longrightarrow$, and 2003: Simulations of the extratropical transition of tropical cyclones: Contributions by the midlatitude upper-level trough to reintensification. Mon. Wea. Rev., 131, 2112-2128, https:// doi.org/10.1175/1520-0493(2003)131<2112:SOTETO>2.0.CO;2.

- , and 2007: Simulations of the extratropical transition of tropical cyclones: Phasing between the upper-level trough and tropical cyclones. Mon. Wea. Rev., 135, 862-876, https:// doi.org/10.1175/MWR3303.1.

Schultz, D. M., and P. N. Schumacher, 1999: The use and misuse of conditional symmetric instability. Mon. Wea. Rev., 127, 2709-2732, https:// doi.org/10.1175/1520-0493(1999)127<2709:TUAMOC>2.0.CO;2.

Thorncroft, C., and S. C. Jones, 2000: The extratropical transitions of hurricanes Felix and Iris in 1995. Mon. Wea. Rev., 128, 947-972, https:// doi.org/10.1175/1520-0493(2000)128<0947:TETOHF >2.0.CO;2.

Wernli, H., R. Fehlmann, and D. Lüthi, 1998: The effect of barotropic shear on upper-level induced cyclogenesis: Semigeostrophic and primitive equation numerical simulations. J. Atmos. Sci., 55, 2080-2094, https://doi.org/10.1175/1520-0469(1998)055<2080: TEOBSO $>2.0 . \mathrm{CO} ; 2$.

Yanase, W., and H. Niino, 2019: Parameter sweep experiments on a spectrum of cyclones with diabatic and baroclinic processes. J. Atmos. Sci., 76, 1917-1935, https://doi.org/10.1175/JAS-D18-0232.1.

- - , K. I. Hodges, and N. Kitabatake, 2014: Parameter spaces of environmental fields responsible for cyclone development from tropics to extratropics. J. Climate, 27, 652-671, https://doi.org/10.1175/JCLI-D-13-00153.1. 